The Ultimate Substance to Cause Cancer Is a Hydrogen Ion and Cancer Cells Stop its Division-Multiplication and Return to Normal Cells by Supplying Oxygen as Hydrogen Acceptor, from Theoretical Research

By

Nobuo Tomizawa

Theoretical Biologist of

Independence in JAPAN 


\section{The Ultimate Substance to Cause Cancer Is a Hydrogen Ion and Cancer Cells Stop its Division-Multiplication and Return to Normal Cells by Supplying Oxygen as Hydrogen Acceptor, from Theoretical Research}

\section{Nobuo Tomizawa \\ Theoretical Biologist of Independence in JAPAN}

\section{ABSTRACT \\ (1)A fundamental viewpoint about cancer cells}

At the present time, methods of treatment for cancer base on the viewpoint that cancer cells make humans deaths, therefore a treatment destroys and kills cancer cells and saves patients. But this conception strikes against the limit on treatment. A cancer cell changed from a normal cell of a human, it does not invade from outside and harm a human like virus. A cancer cell is derived from a human cell, therefore when we aim to destroy cancer cells, this attack damages to other normal cells and weaken vital energy of a human. Here there is the limit of treatment for cancer.

In opposition to these thoughts, this theory is based on the viewpoint that normal cells faced to critical situation to live and changed its system to survive under the situation and that are certainly cancer cells. The reason why a cancer cell has tough vitality to make a human death is the result to acquire the ability for existing under such a situation. Therefore a treatment for cancer is not to destroy and to kill but to remove factors that prevent normal cells from living orderly. Then cancer cells become unnecessary to derive a tough vitality. And its rapid division and multiplication will stop and return to normal cells.

I built the theoretical model as follows.

A cell becomes lack of oxygen that is necessary to live. Then hydrogen ions emerge in that cell. Hydrogen ions promote division and multiplication. Take these hydrogen ions out by supplying oxygen like a normal cell doing, and cancer cells will stop division and return to normal cells.

This research intends to explain by facts already known and prove this model on,

(1) how hydrogen ions emerge in cells?

(2) how hydrogen ions promote cell division?

Then 
(3) how a treatment for cancer is possible?

\section{(2)The division of works of building theoretical models and experiments on biology and medical science}

Some historical discoveries on physics have walked on the process that a theoretical research predicts the existence of materials or the law and some experiments prove it. Physics is divided into two areas. One is theoretical physics that builds theoretical models and another is experimental physics that proves those models by experiments.

In medical science and biology, usually one researcher builds a supposition and proves it by experiments. Theoretical work and verification by experimental work are not divided. A theoretical model without experimental proof is not enough recognized its medical or biological value.

However more multiple researches will be possible by dividing theoretical work to build theoretical models and experimental work to verify it in the field of cancer that is not solved an ultimate cause and a mechanism to change from normal cells. And it should value theoretical researches that are not yet verified by experiments.

This treatise is the theoretical model that is not proved by experiments. I illustrated specific ways for experiments to prove in Chapter 4, "The principle and practical methods of medical treatment for cancer of human beings, (1)Supply oxygen to cultured cancer cells, and multiplication of cancer cells will stop".

I hope that scientists of medical science and biology would prove it by experiments.

And I develop this theoretical model as followings.

\section{CONTENTS}

\section{Chapter 1}

The phenomenon that the accumulation of hydrogen ions occurs in a cell

1. Confirming the process of generating energy

2. A cell accumulates hydrogen ions under the condition of lack of oxygen

3 . There are three types that oxygen becomes shortage in cells

4. Irradiating radiation to a cell generates hydrogen ions

(1) The meaning to explain that hydrogen ions emerge by radiation in a cell

(2) The phenomenon that radiation causes to cells is the generation of hydrogen ions 


\section{Chapter 2}

Hydrogen ions play the main role in cell division

1. The mechanism of separation of thymine and adenine

(1) Thymine as a tautomer

(2) Partition of hydrogen bond between thymine and adenine in DNA

(3) Adenine as a tautomer

(4) Partition of hydrogen bond between adenine and thymine in DNA

(5) Summary and illustration

2. Separation of hydrogen bond between cytosine and guanine

(1) Cytosine as a tautomer

(2) Partition of hydrogen bond between cytosine and guanine in DNA

(3) Guanine as a tautomer

(4) Partition of hydrogen bond between guanine and cytosine in DNA

(5) Summary and illustration

3. Separation of DNA

4. Tautomerically shifted DNA is recovered by RNA

(1) Tautomerically shifted base of DNA bonds with RNA

(2) The recovery of bases of DNA that were shifted tautomerically

(3) It is possible that the parts of bases not bonded with RNA primers recover from its tautomeric shift by delivering hydrogen ions into bases

(4) It is natural to think that RNA primer does not bond to leading strand

(5) Summary by illustration

\section{Chapter 3}

The rate of cell division is decided by a quantity of hydrogen ions

1. Redefine the process of cell cycle regarding to a quantity of hydrogen ions

(1) Subdividing cell cycle

(2) Movement of a quantity of hydrogen ions at each period of cell cycle

(3) Movement of a quantity of hydrogen ions at cell cycle

2. The definition of cancer

(1) Cancer cell is the cell that a quantity of hydrogen ions of daughter-cell right after cell division already exceeds the level to start the cell division

(2) Expressing the state of a quantity of hydrogen ions in a cancer cell by a chart

Chapter 4

The principle and the practical methods of a treatment for cancer

1. A cure for cancer means stopping the cell division of cancer cells

2. The principle of a treatment for cancer is to supply oxygen to cancer cells and to remove hydrogen ions

3. The experiments in cultured cells and the practical methods of medical 
treatment for cancer of human beings

(1) Supply oxygen to cultured cancer cells, and multiplication of cancer cells will stop

(1) Supply oxygen to cultured cancer cells, and cancer cells stop its multiplication and return to normal cells

(2) Fill cancer cells of a laboratory dish with hemoglobin, and supply oxygen

(2) Methods of medical treatment for cancer of human beings

(1) Breathe $100 \%$ oxygen and heighten density of oxygen in blood, promote the blood circulation and supply oxygen to cancer cells

(2) Supply oxygen in high density with high pressure

(3) Supply oxygen to myeloid blood and cure myeloid leukemia

(4) Supply oxygen to digestive organs with catheters

(5) Supply oxygen with super-bubble water that contains super-minute oxygen through the digestive organ

(6) Change a hydrogen ion into a hydrogen molecule by offering an electron to a hydrogen ion for a treatment of lung cancer

\section{REFERENCES}

\section{Chapter 1}

The phenomenon that the accumulation of hydrogen ions occurs in a cell

\section{Confirming the process of generating energy}

It has been made clear that energy production is performed through the following process as Fig.1-1.

In the first place, glucose changes into pyruvic acid through Embden-Meyerhof pathway. In this process, when two glyceraldehydes-3-phosphate change into two 1,3-diphosphoglycerate, two $\mathrm{NAD}^{+}$take four hydrogen ions and four electrons from glyceraldehydes"3-phosphate, and change into NADH and two hydrogen ions.

(glyceraldehydes-3-phosphate)

(1,3-diphosphoglycerate)

$2 \mathrm{CHOCO}_{2} \mathrm{OCH}_{2} \mathrm{OPO}_{3} \mathrm{H}_{2}$

$2 \mathrm{NAD}^{+}$

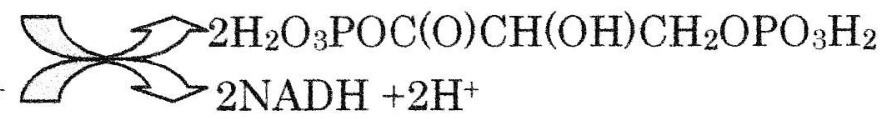

Two NADH and two hydrogen ions select their pathway from two kinds, depending upon quantity of oxygen in the cell. If oxygen exists enough for perfect oxidation, two NADH and two hydrogen ions are oxidized through the respiratory chain. If oxygen is insufficient, they hand four hydrogen ions and four electrons over to two molecules of pyruvic acid. And two NADH and 
Fig.1·1

Embden-Meyerhof pathway

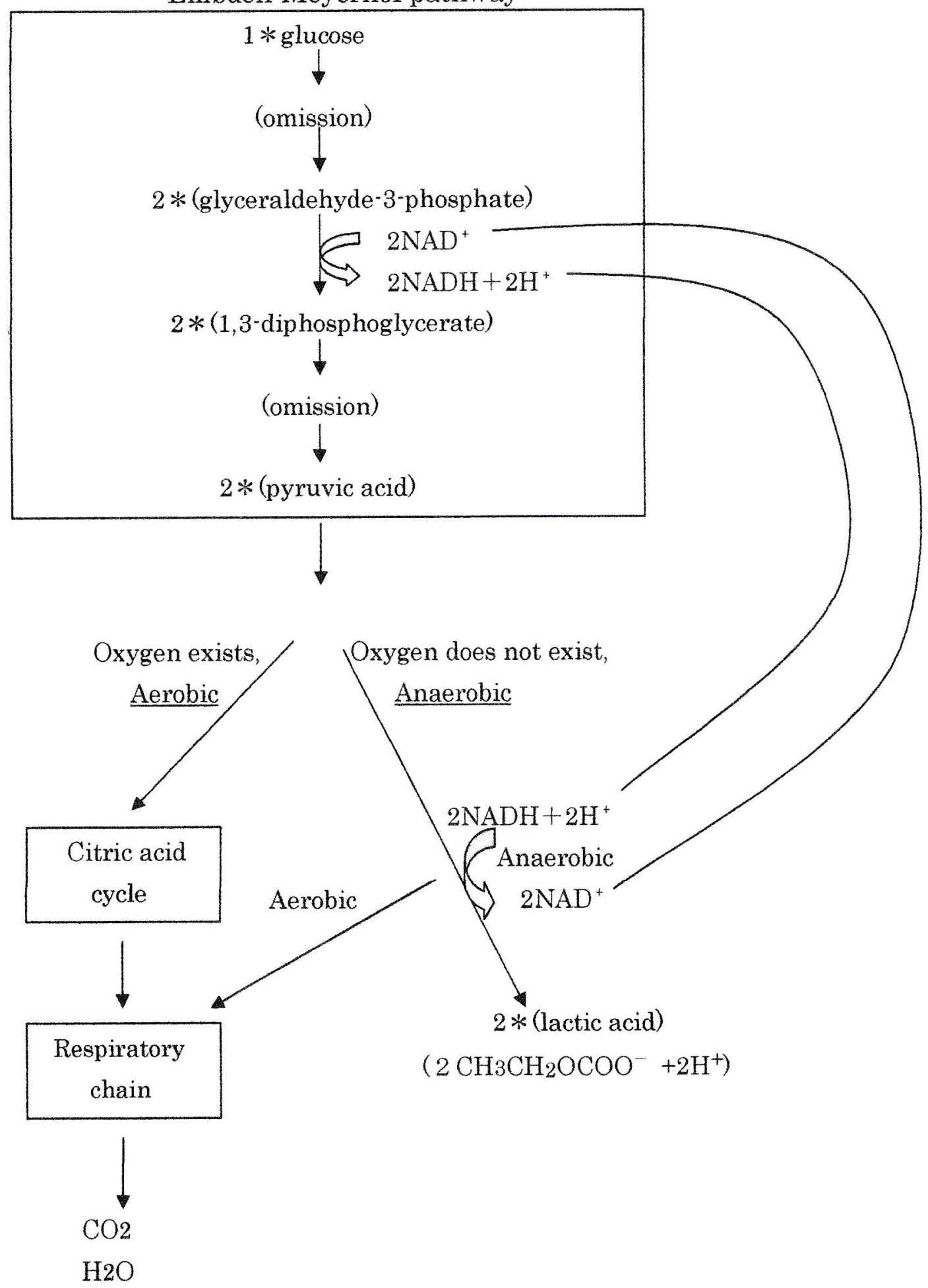


two hydrogen ions change back to two $\mathrm{NAD}^{+}$

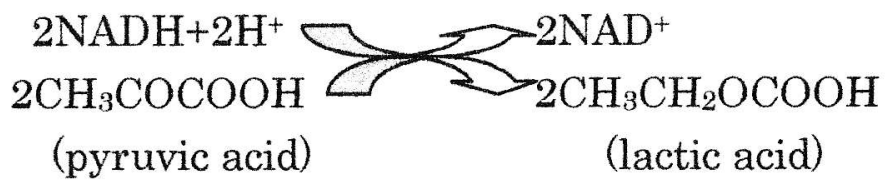

\section{A cell accumulates hydrogen ions under the condition of lack of oxygen}

Thus, hydrogen ions derived from Embden- Meyerhof pathway are absorbed to lactic acid. Lactic acid exists with ionizing and extricating a hydrogen ion as

$$
\mathrm{CH}_{3} \cdot \mathrm{CH}_{2} \mathrm{O} \cdot \mathrm{COO}^{-}+\mathrm{H}^{+}
$$

Therefore if cells will produce energy in the condition of oxygen shortage for a long time, lactic acid is accumulated there. Also that means accumulation of hydrogen ions.

Thus, hydrogen ions are generated and gradually accumulated in anaerobic respiration at a cell.

The anaerobic energy production will be carried out in the conditions as followings.

\section{There are three types that oxygen becomes shortage in cells}

Glucose proceeds into Embden-Meyerhof pathway, and changes to pyruvic acid, and it goes to aerobic respiration or fermentation according to quantity of oxygen.

Two molecules of pyruvic acid consume five molecules of oxygen for perfect oxidation.

$$
\begin{aligned}
\text { Pyruvic acid : Oxygen } & =2: 5 \\
\text { Oxygen } / \text { Pyruvic acid } & =5 / 2
\end{aligned}
$$

In the condition that oxygen comes to be relatively short to pyruvic acid, their ratio will be less than 5/2. Relative shortage of oxygen will occur in three cases. And these cases are investigated by using models.

(1) Pyruvic acid is invariable, oxygen decreases

A quantity of supplied pyruvic acid is invariable, but oxygen becomes less than five molecules per two molecules of pyruvic acid. Therefore perfect oxidation will not be done.

This phenomenon in cells occurs in case that the oxygen supply is prevented by cancerogenic factors or circumstances that a living body is situated. For example, cells of epithelial tissues such as skin or respiratory organs obtain oxygen directly from the air. If epithelial tissues are covered by tar, the supply of oxygen becomes short however the respiratory substrate supplied 
by blood does not change.

(2) A quantity of oxygen is invariable, pyruvic acid increase

A quantity of oxygen is invariable, but more than two molecules of pyruvic acid to five molecules of oxygen are supplied to a cell. Also in this case, oxygen is relatively short to pyruvic acid, therefore anaerobic energy production will be occurred. For example, in experiment this phenomenon occurs by injecting liquid of concentrated grape sugar into a muscle. Dr. Yasuo Nishiyama carried out this experiment and verified the incidence of sarcoma.

(3) An increase of pyruvic acid is much more than that of oxygen

In a living body, when an energy demand of certain cells rises, supply of both respiratory substrate and oxygen will increase. The degree of this correspondence can be called "elasticity of supply". Elasticity of supply is indicated as followings.

$\mathrm{Es}=\Delta \mathrm{ss} / \triangle \mathrm{ed}$

Es : elasticity of substrate supply

$\triangle \mathrm{ss}$ : quantity of increased substrate supply

$\triangle \mathrm{ed}:$ quantity of increased energy demand

Similarly

$\mathrm{Eo}_{\mathrm{o}}=\Delta \mathrm{os} / \triangle \mathrm{ed}$

Eo : elasticity of oxygen supply

$\triangle \mathrm{os}:$ quantity of increased oxygen supply

Supposing elasticity of substrate is much more than that of oxygen, namely Es $>$ Eo, the following phenomenon will occur.

$$
\begin{gathered}
\text { Es }>\text { Eo } \\
=\Delta \mathrm{ss} / \Delta \mathrm{ed}>\Delta \mathrm{os} / \triangle \mathrm{ed} \\
=\Delta \mathrm{ss}>\triangle \mathrm{os} \quad \begin{array}{l}
\text { (This means that increased supply of respiratory } \\
\text { substrate is much more than increased supply of } \\
\text { oxygen) }
\end{array}
\end{gathered}
$$

Therefore

$$
\text { Oxygen / pyruvic acid }<5 / 2
$$

When an energy demand rises, a supply of both respiratory substrate and oxygen will increase. Moreover elasticity of substrate supply Es is much more than that of oxygen supply Eo. Therefore substrate will be supplied much more than oxygen. Substrate, as to glucose here, changes into pyruvic acid through Embden-Meyerhof pathway. Therefore pyruvic acid increases too much to be oxidized completely.

This situation can occur in the case that the circumstance of a living body makes the energy demand increase to a particular organ by imposing a 
continuous load.

These three conditions cause anaerobic respiration. As the result, lactic acid is formed and hydrogen ions will accumulate.

There can be another way that generates hydrogen ions without the route of anaerobic respiration. The carcinogenesis by radiation is the way that generates hydrogen ions directly in cells. It will be developed in next section.

\section{Irradiating radiation to a cell generates hydrogen ions}

\section{(1)The meaning to explain that hydrogen ions emerge by radiation in a cell}

The incidence of cancer is not caused only by factors that influence to the process of an energy generation. Irradiating radiation to a human body causes cancer at a high probability. This phenomenon is unrelated to the energy generation.

Then, if the phenomenon caused by radiation connects to carcinogenesis by the energy generation, it is what the entrances, functions by factors of carcinogenesis are different but the exit, the carcinogenesis as a result is the same. If these two processes, carcinogenesis by radiation and an energy generation connect at the same point, it means that it completes to explain the phenomenon of carcinogenicity by one principle.

The next section tried this explanation.

(2)The phenomenon that radiation causes to cells is the generation of hydrogen ions

Hitting radiation against a water molecule strikes an electron of water out, and finally a hydrogen ion emerges through the following process.

(1) Radiation $\longrightarrow \mathrm{H}_{2} \mathrm{O} \rightarrow \mathrm{H}_{2} \mathrm{O}^{+}+\mathrm{e}^{-}$

(2) $\mathrm{H}_{2} \mathrm{O}^{+}+\mathrm{H}_{2} \mathrm{O} \rightarrow \mathrm{OH} \cdot+\mathrm{H}_{3} \mathrm{O}^{+}$

(3) $\mathrm{H}_{3} \mathrm{O}^{+}+\mathrm{e}^{-} \rightarrow \mathrm{H} \cdot+\mathrm{H}_{2} \mathrm{O}$

[ $\mathrm{OH} \cdot$ : free hydroxyl $\mathrm{H} \cdot$ : free radical hydrogen]

Further, radiation irradiates to hydrogen and an electron of a water molecule is struck out, hydrogen divides to a hydrogen ion and an electron.

(4) Radiation

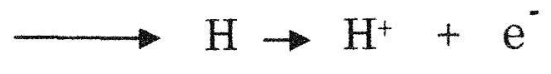

$$
[\mathrm{H} \cdot=\mathrm{H}]
$$

(Referenced and edited from "Why is a human being weak to radiation?" 
Souhei Kondoh 1986)

In a conclusion, radiation irradiates to a molecule of water and hydrogen emerges then it becomes a hydrogen ion.

Cells contain enough water therefore irradiating radiation to cells generates hydrogen ions in cells.

Thus it is clear that hydrogen ions emerge and accumulate in cells with not only anaerobic respiration but radiation. The mechanism to cause cancer connects to one point that hydrogen ions emerge in cells. Then we must explain how hydrogen ions cause cancer.

The menace of cancer is its high rate of cell division. Therefore the solution of the mechanism of carcinogenesis is to resolve the mechanism of cell division and a factor to decide its rate.

Next I would like to present a model how hydrogen ions concern to cell division.

\section{Chapter 2}

Hydrogen ions play the main role in cell division

The primary phenomenon preceding all of cell division is DNA replication. That begins with dissociation of DNA double helix into the single. As already known, DNA forms double helix linking thymine and adenine by hydrogen bond as well as cytosine and guanine. The mechanism that double helix unties can be explained with combining facts already known as followings.

\section{The mechanism of separation of thymine and adenine}

\section{(1) Thymine as a tautomer}

As already known, thymine has a property of tautomerism. It is the property that arrangements of component molecules are not fixed and not unchangeable but can change the positions of hydrogen as Fig.2-1.

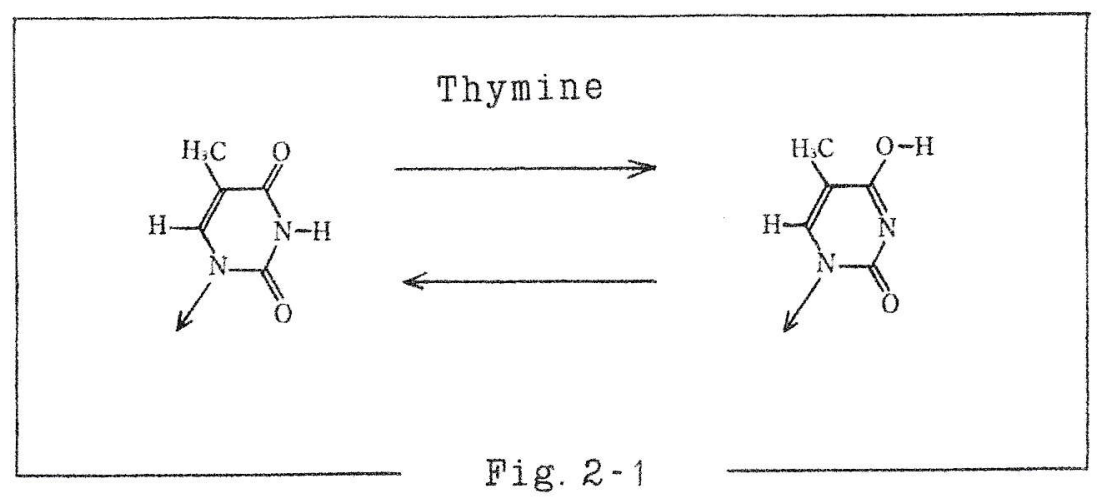

Then this property causes the following phenomenon. In the state of Fig.2-2, if a free hydrogen ion comes from outside attracted electrically and sit in the 
potion "a", the hydrogen in the position " $b$ " will separate as an ion according to the property of tautomer. It can call this movement "the tautomeric shift".

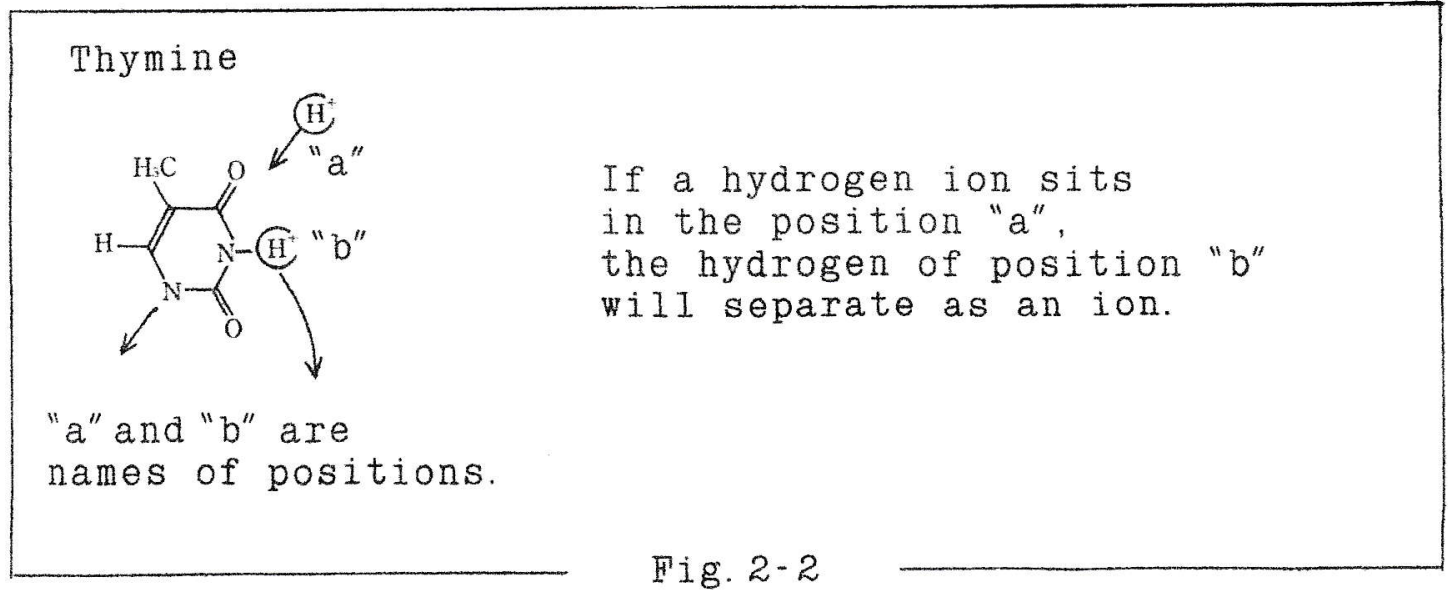

The reverse is also possible as Fig. $2 \cdot 3$.

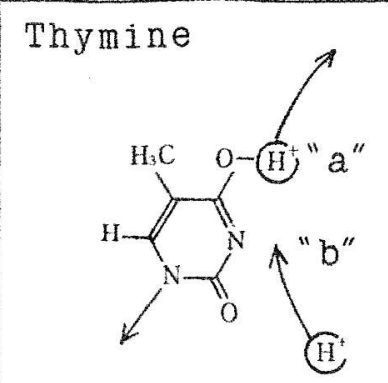

The hydrogen in the position of "a" separates, when another hydrogen ion sits in the position " $b$ ".

\section{Fig. $2 \cdot 3$}

\section{(2)Partition of hydrogen bond between thymine and adenine in DNA}

As already elucidated, one of the constituent units of DNA is the hydrogen bond between thymine and adenine in the two points, " $a$ " and "b" as Fig.2-4.

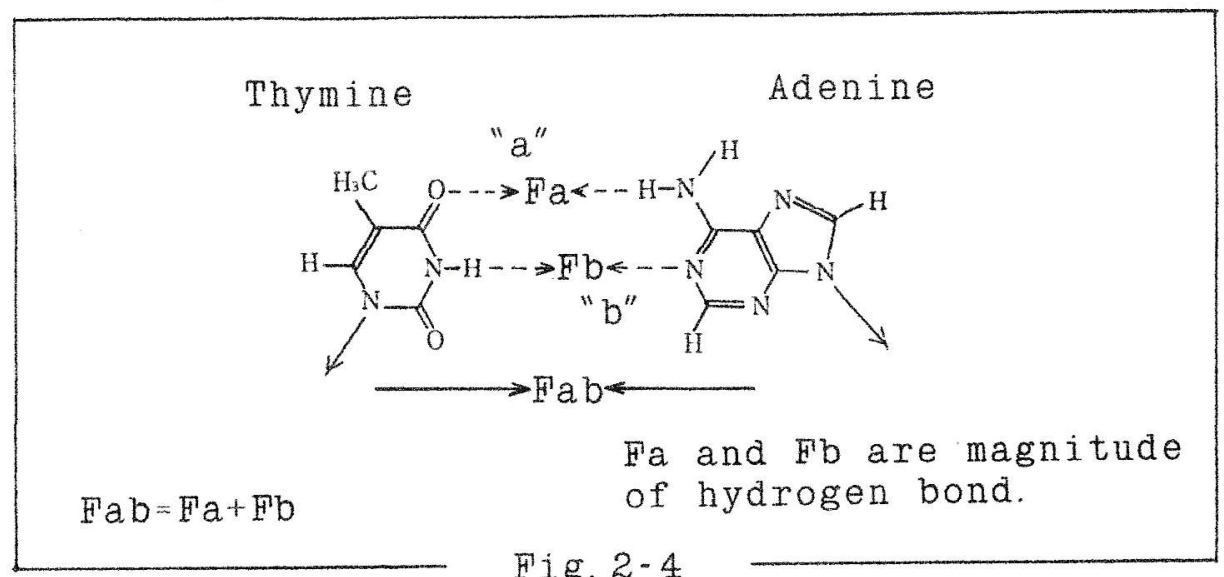

In Fig.2-5, when a hydrogen ion approaches from outside to the oxygen $\mathrm{O}$ in the position " $a$ " and combines with $O$, thymine releases hydrogen in the 
position " $b$ " as an ion because of tautomer. The position of hydrogen changes thus.

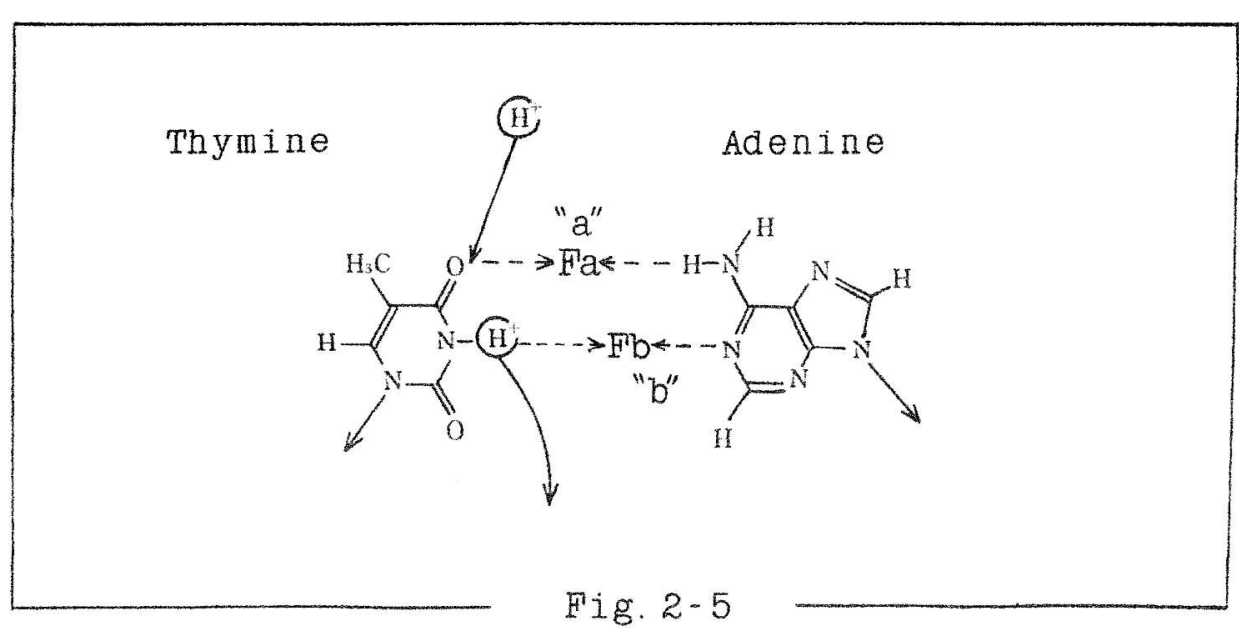

Its result is Fig. $2 \cdot 6$. In Fig. $2 \cdot 6$, the hydrogen of thymine and that of adenine in the position "a" will repel each other because of the same electric pole, both positive. Its magnitude is represented with $\triangle \mathrm{Fa}^{\prime}$. (mark $\Delta$ means repulsion)

Similarly in the position " $b$ ", the nitrogen $\mathrm{N}$ of thymine and that of adenine repel, because of the same pole of electric charge, both negative. Its magnitude is represented with $\triangle \mathrm{Fb}^{\prime}$. Thymine and adenine repel in the position "a" and "b" with the aggregate forth $\triangle F$ ab' summed $\triangle F a$ ' and $\triangle F b$ '. Therefore the hydrogen bond between thymine and adenine will break and two bases will separate.

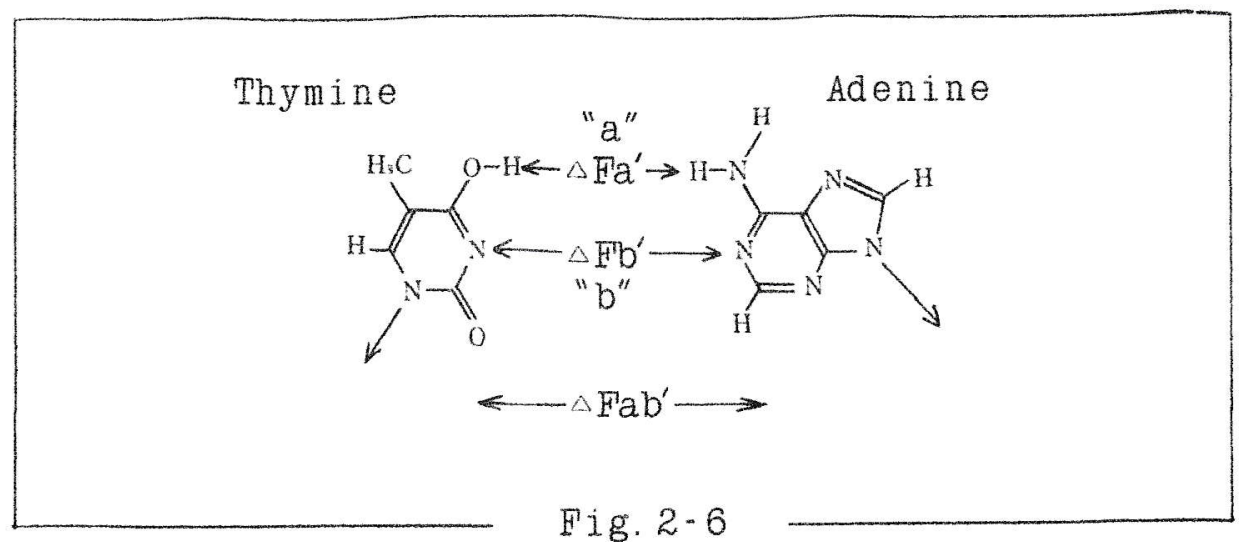

Thus thymine and adenine change its positions of hydrogen with the property of tautomerism and hydrogen bond parts and two bases divide. It is possible that these mechanism works.

\section{(3)Adenine as a tautomer}

Adenine is a tautomer as well as thymine. Therefore it can shape two patterns as Fig.2-7. It can be thought that this change of patterns is caused as follows. 


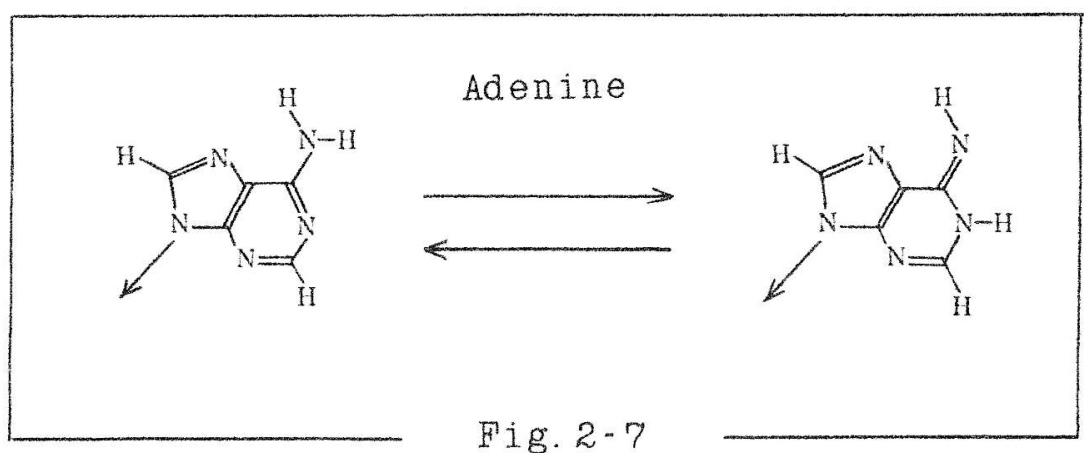

In Fig.2-8, when a free hydrogen ion approaches to the position " $b$ " of adenine, it will combine with nitrogen of adenine. Then the hydrogen in the position "a" will separate from there because of the characteristic of a tautomer. Thus adenine changes to another pattern that a position of hydrogen is different. This is called the tautomeric shift.
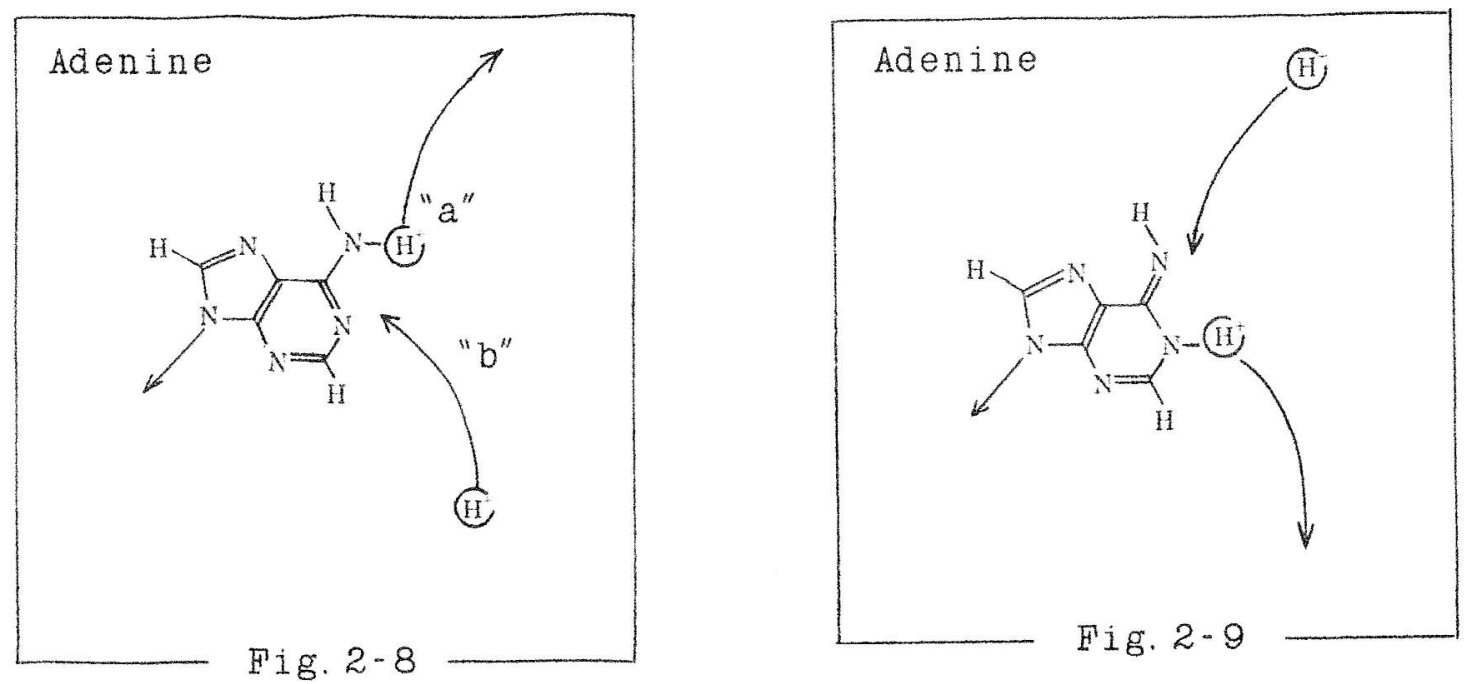

Fig.2-9 indicates its reverse movement that tautomerically shifted adenine returns to the former situation.

\section{(4)Partition of hydrogen bond between adenine and thymine in DNA}

In DNA, adenine and thymine combine with hydrogen bond as Fig. $2 \cdot 10$. Fa is the magnitude of the force of hydrogen bond in the position "a" between the hydrogen of adenine and the oxygen of thymine. $\mathrm{Fb}$ is the magnitude of the force of hydrogen bond in the position " $b$ " between the nitrogen of adenine and the hydrogen of thymine. Fab is the resultant force of $\mathrm{Fa}$ and $\mathrm{Fb}$. 


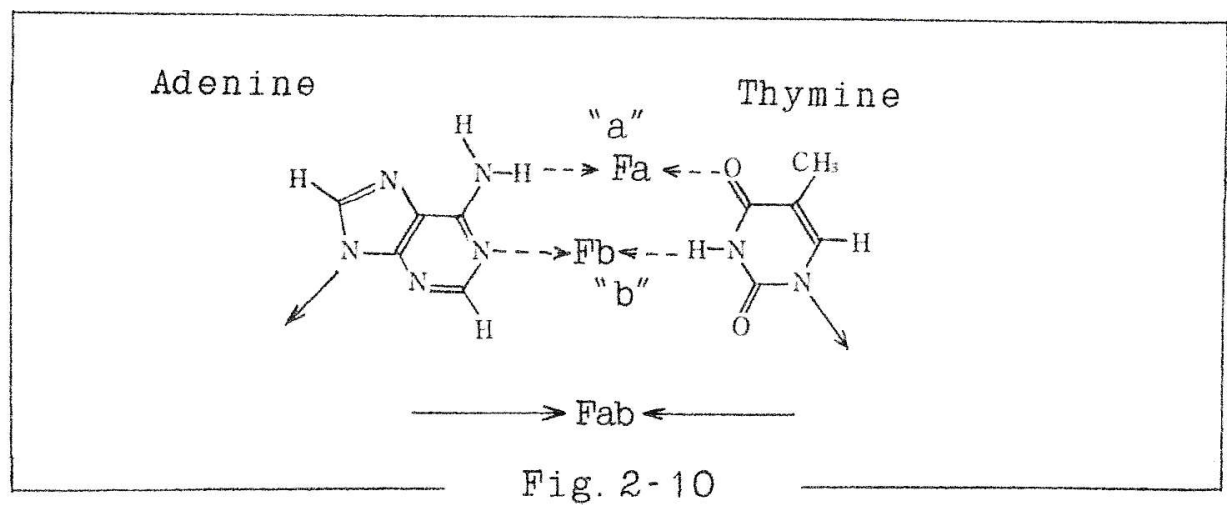

In Fig.2-11, a hydrogen ion approaches to adenine and combines with nitrogen in the position " $b$ " and adenine releases hydrogen of the position " $a$ " as a hydrogen ion because of a characteristic of tautomer.

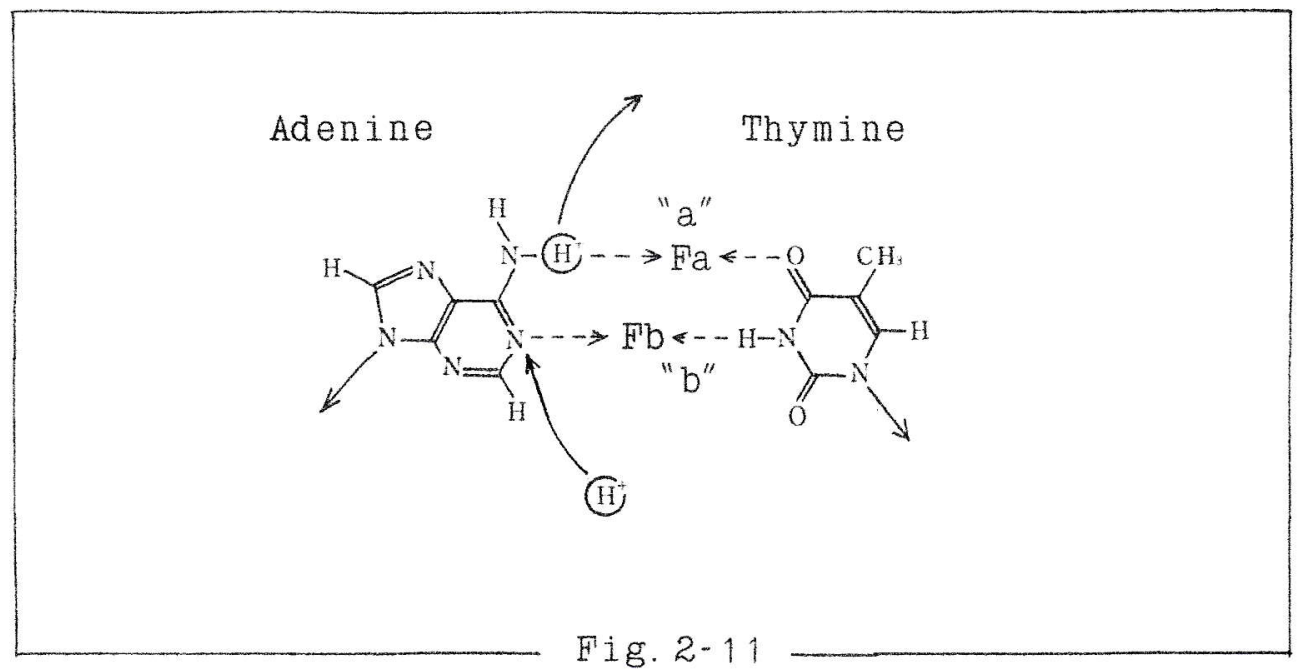

By this tautomeric shift, the relation of adenine and thymine becomes like Fig. 2-12.

In the position "a", nitrogen of adenine and oxygen of thymine will repel with the force $\triangle \mathrm{Fa}$ " due to both negative electric charges. In the position "b", two hydrogen atoms repel each other with the force $\triangle F$ " because of both positive electric charges. And adenine and thymine will repel with the force $\triangle \mathrm{Fab}$ ", that is the resultant force of $\triangle \mathrm{Fa}$ " and $\triangle \mathrm{Fb}$ ".

Thus hydrogen bond is severed by a hydrogen ion and those two bases will separate out.

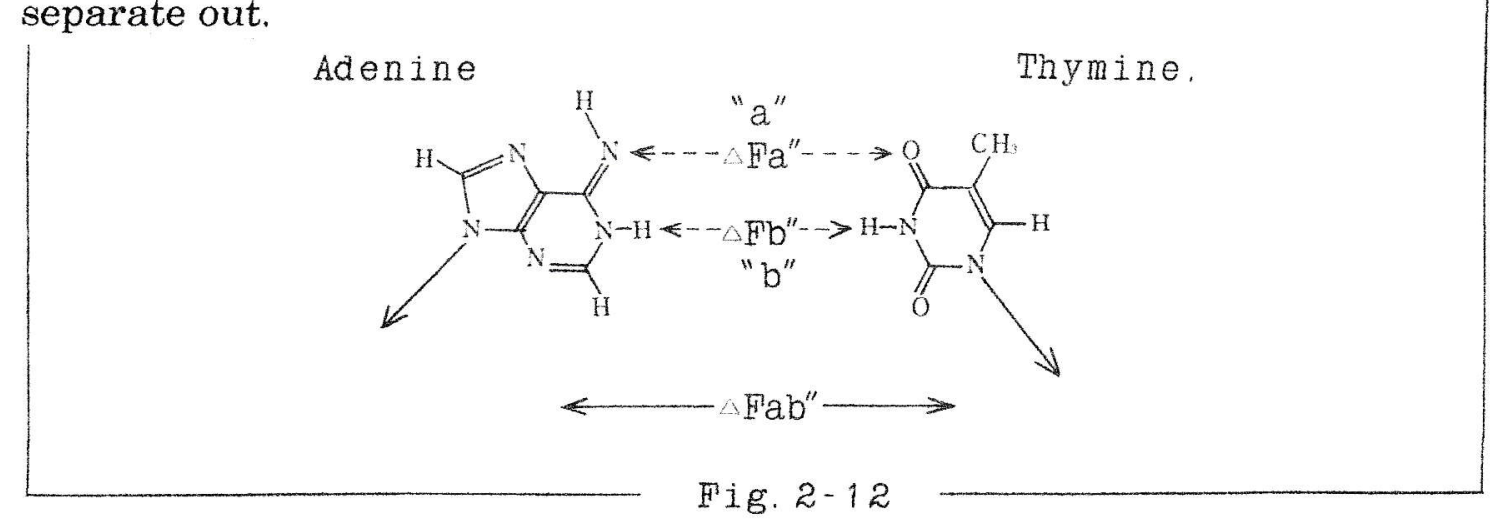




\section{(5)Summary and illustration}

The preceding thought can be summarized and illustrated as Fig.2-13.

(1) In DNA, thymine and adenine combine by hydrogen bond.

(2) A free hydrogen ion combines with thymine, and another hydrogen parts from thymine as an ion.

(3) As a result of changing the hydrogen's position, thymine and adenine will repel each other.

(4) The same phenomenon occurs in adenine, and two bases will repel and separate.

(1) Fig. 2-13

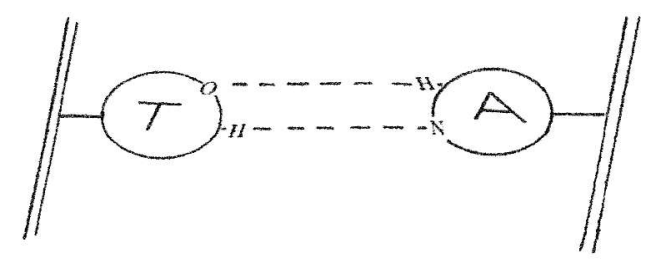

(2)

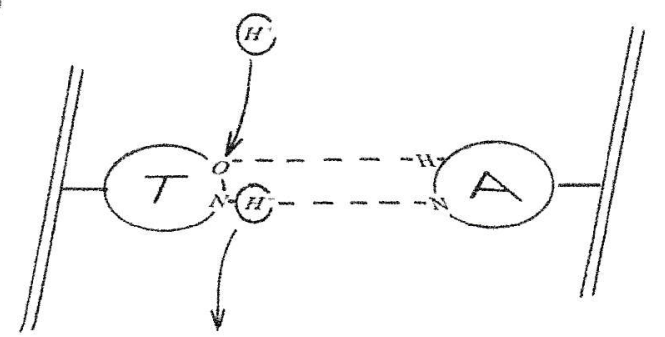

(3)

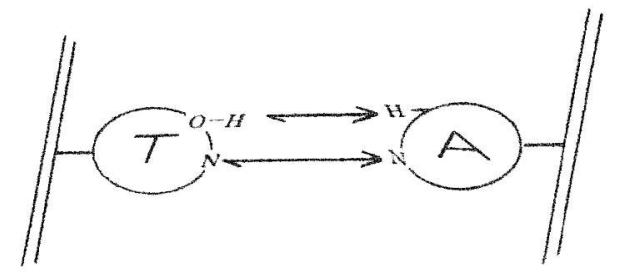

(4)

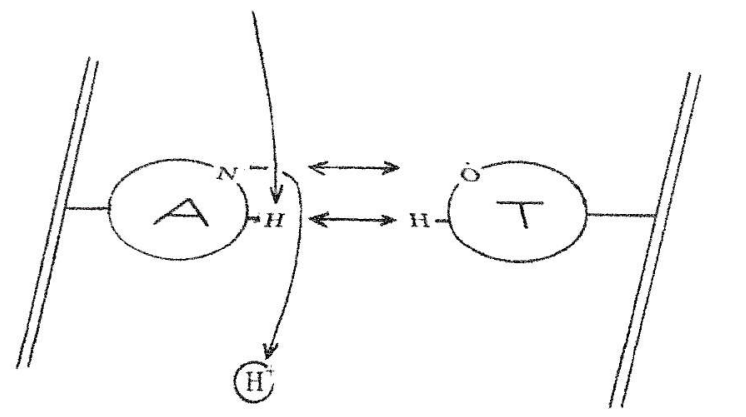


(5) Through these processes, double helix will begin to decompose into each a single thread in part of DNA, thymine and adenine.

(5)

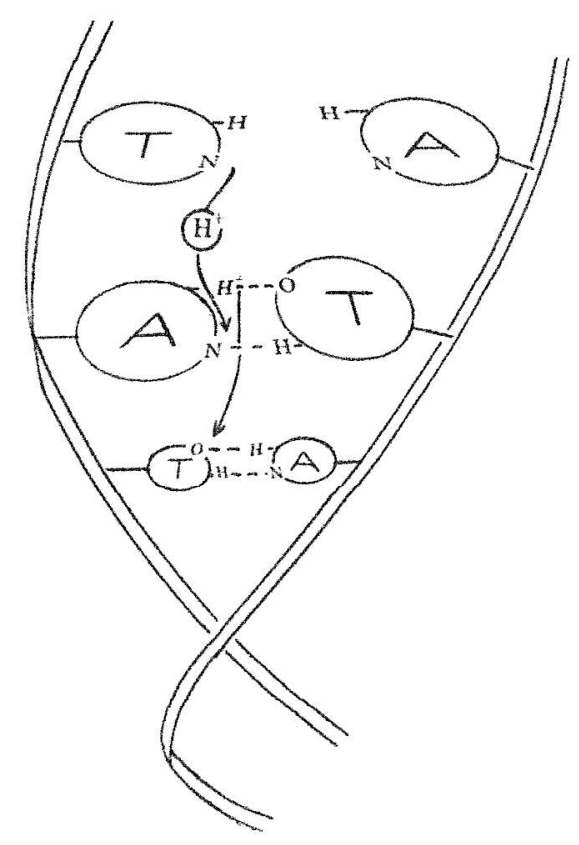

In the result of separation of DNA double helix by severing hydrogen bond, the positions of hydrogen of thymine and adenine are left as they shifted tautomerically. The mechanism that these shifted bases recover will be evolved at chapter 2 section 4 .

\section{Separation of hydrogen bond between cytosine and guanine}

\section{(1)Cytosine as a tautomer}

One of the constituent elements of DNA, cytosine is also a tautomer that has two patterns. The position of hydrogen can alter from " $\mathrm{c}$ " to " $\mathrm{e}$ " or from " $\mathrm{e}$ " to "c" as Fig.2-14.

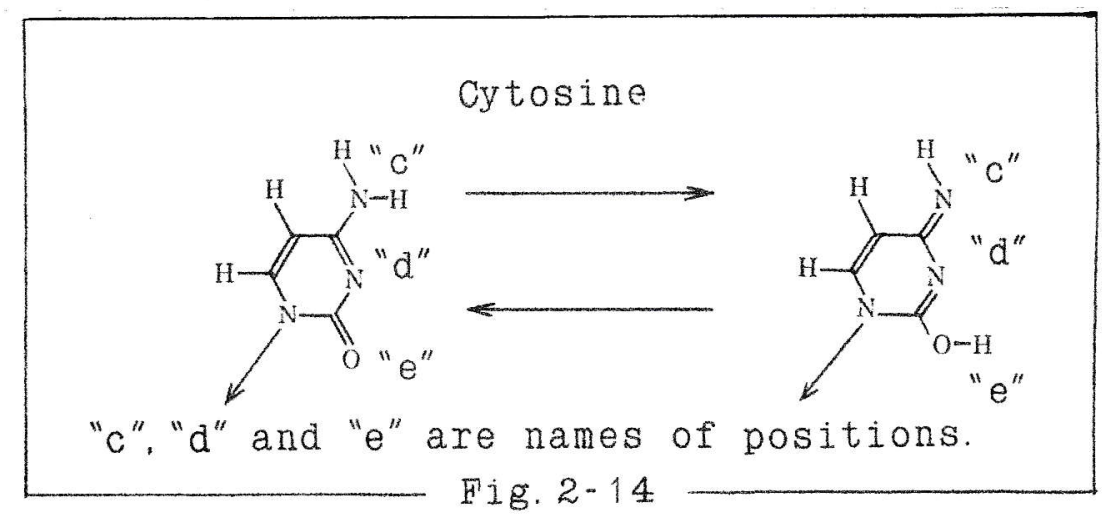

Note: I have not been able to confirm a pattern of cytosine that has hydrogen in position " $\mathrm{c}$ " in literatures. But it will be possible that hydrogen attaches there. Now, I assume that cytosine can have hydrogen in " $c$ ", and step the investigation forward. 
In Fig. 2-15 if a hydrogen ion enters the position "e" and combines with oxygen, the other hydrogen ion will separate from the position "c".

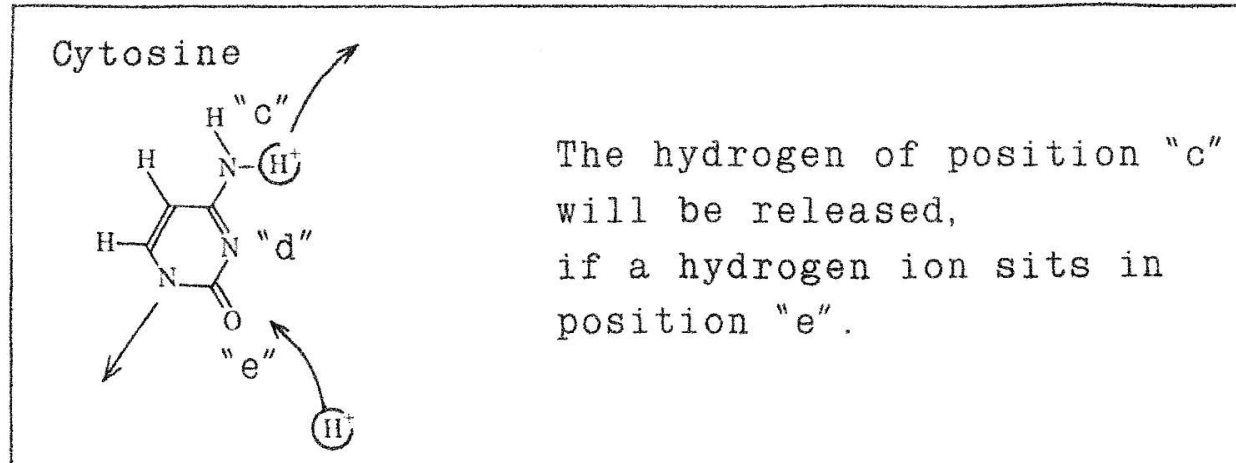

Fig. $2-15$

Similarly, in Fig.2-16, when a hydrogen ion enters to the position "c" and combines with nitrogen, the other hydrogen of the position "e" will release as an ion.

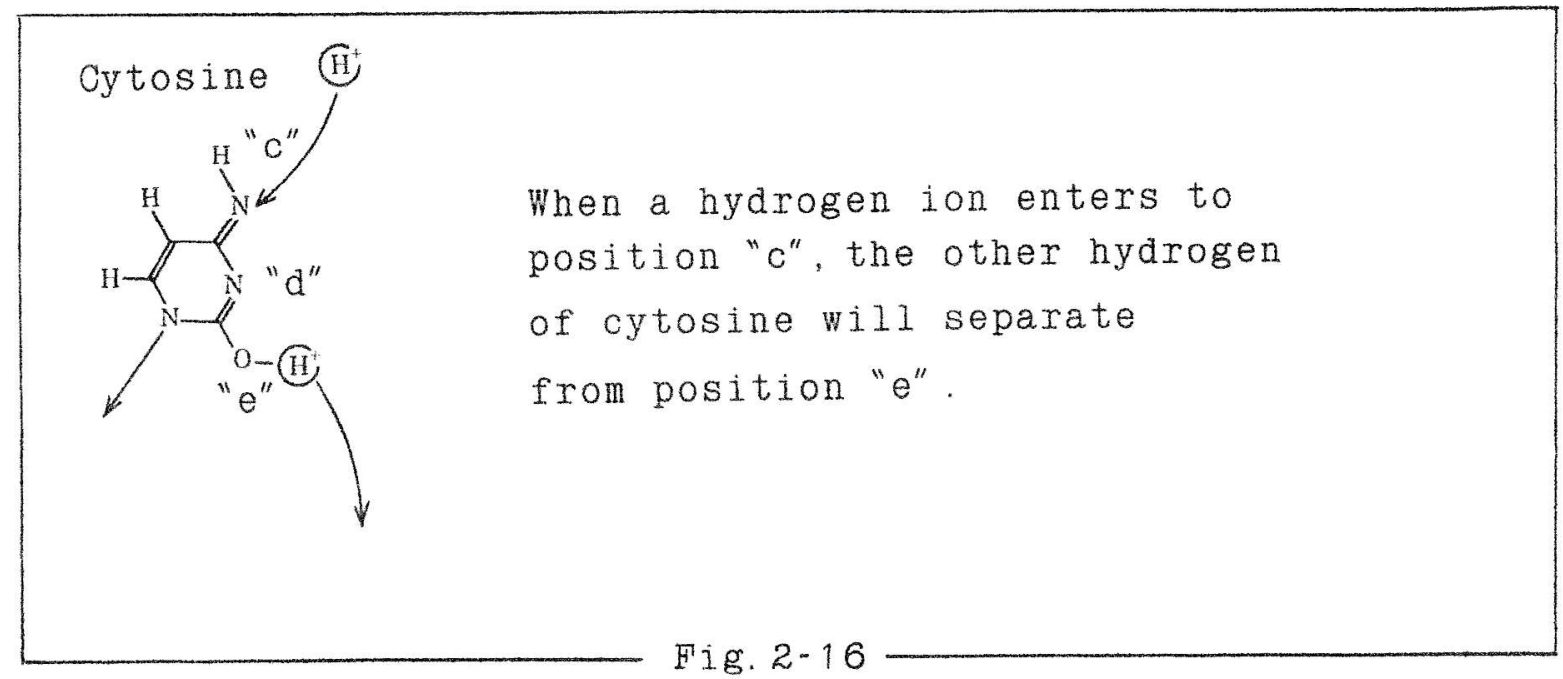

\section{(2)Partition of hydrogen bond between cytosine and guanine in DNA}

In DNA, cytosine combines with guanine by hydrogen bond in three points "c", "d" and "e" as Fig.2-17.

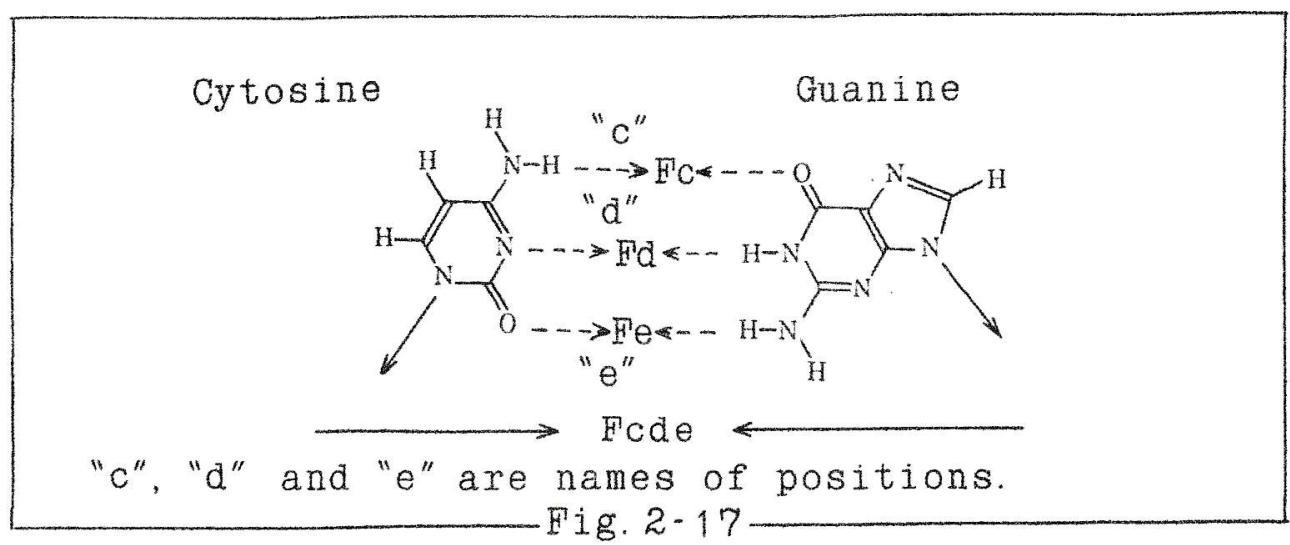

Like as Fin. $2 \cdot 18$, when a free hydrogen ion approaches to the position "e" from outside and combines with oxygen of cytosine, cytosine will release its 
inner hydrogen as an ion because of the characteristic of a tautomer, that the positions of hydrogen between the position " $\mathrm{e}$ " and the position " $\mathrm{c}$ " are exchangeable. (Fig.2-19)
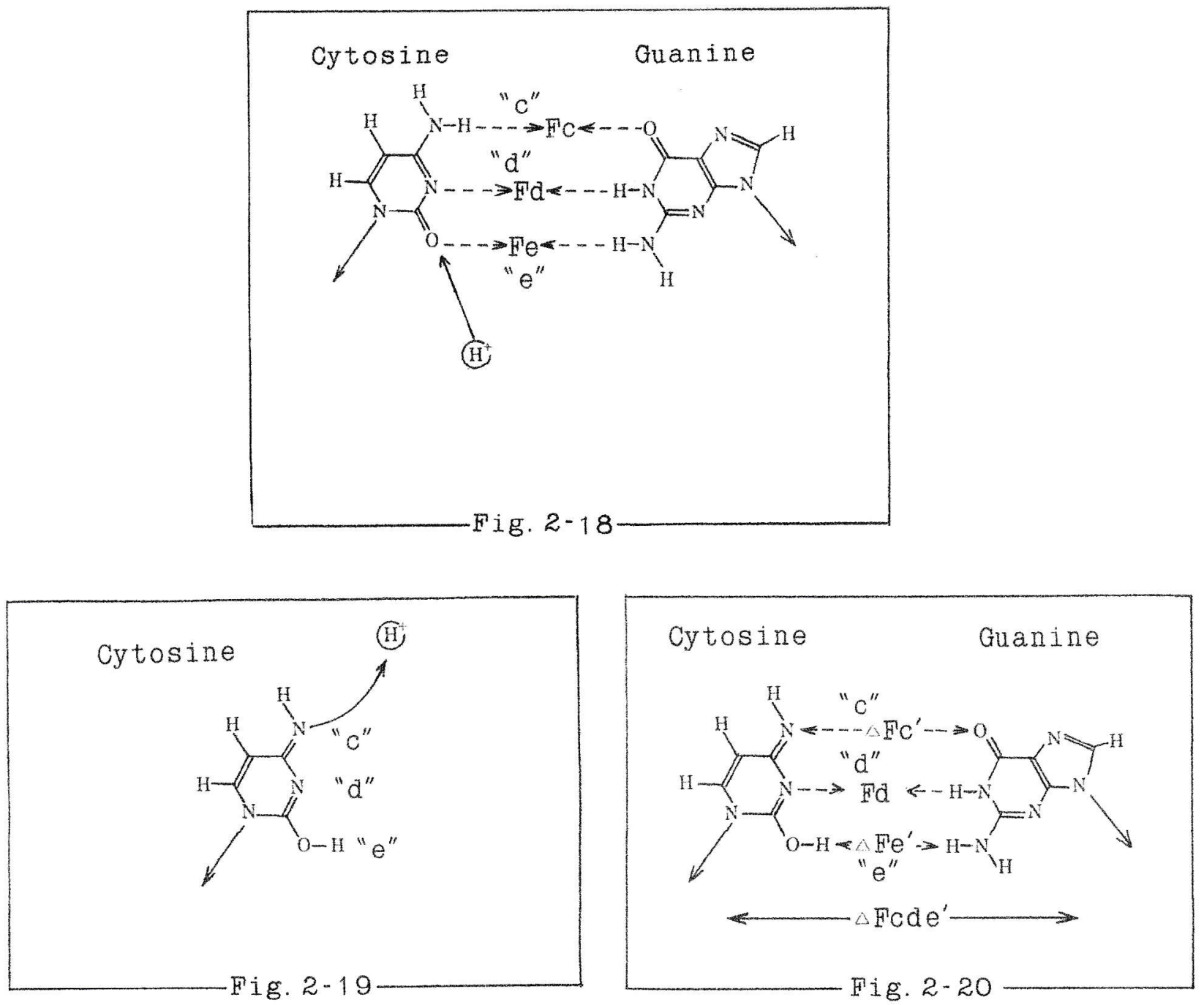

Through these processes, hydrogen bond of cytosine and guanine becomes the relation as Fig.2-20. In the position "c", nitrogen of cytosine and oxygen of guanine repel because of their both negative electric charges. Its magnitude is represented with $\triangle F c^{\prime}$. The sign', $\triangle$ means repulsion. Also in the position "e", the hydrogen of cytosine and that of guanine will repel each other due to both positive electric charges. Its magnitude is represented with $\triangle \mathrm{Fe}^{\prime}$.

In the position " $d$ ", the nitrogen of cytosine and the hydrogen of guanine attract each other with magnitude $\mathrm{Fd}$ as they were.

Between cytosine and guanine, the force of repulsion is $\triangle F^{\prime}+\triangle F e^{\prime}$, and the force of attraction is $\mathrm{Fd}$.

$$
\left[\triangle \mathrm{Fc}^{\prime}+\triangle \mathrm{Fe}^{\prime}\right]>\mathrm{Fd}
$$


Therefore the total force, $\triangle \mathrm{Fc}^{\prime} \triangle \mathrm{Fe}$ ' and $\mathrm{Fd}$, is repellent.

$$
\text { So, } \triangle F c d e^{\prime}=\triangle F c^{\prime}+\triangle F e^{\prime}+F d
$$

Thus cytosine and guanine repel with the magnitude, $\triangle \mathrm{Fcde}$ ' so that their hydrogen bond severs and two bases come to separate.

\section{(3)Guanine as a tautomer}

Guanine is also a tautomer, which can exchange the positions of hydrogen between the position "c" and the position "e" as Fig.2-21.

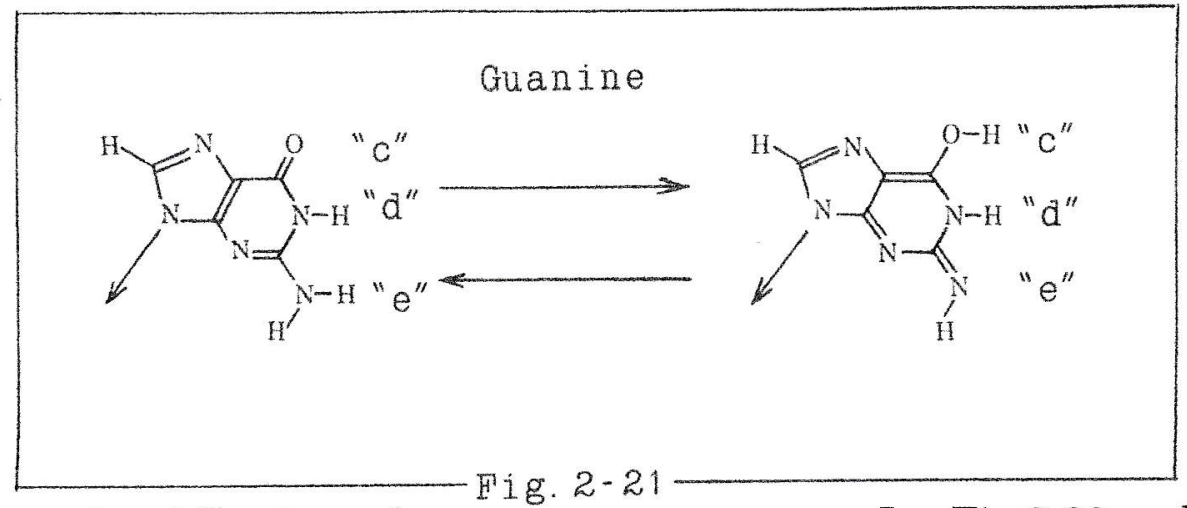

Therefore the following phenomenon can occur. In Fig.2-22, when an independent hydrogen ion approaches to the oxygen of the position " $\mathrm{c}$ ", it will attach to that oxygen by covalent bond. Then the hydrogen in the position " $\mathrm{e}$ " leaves there as an ion because of the characteristic of tautomerism.
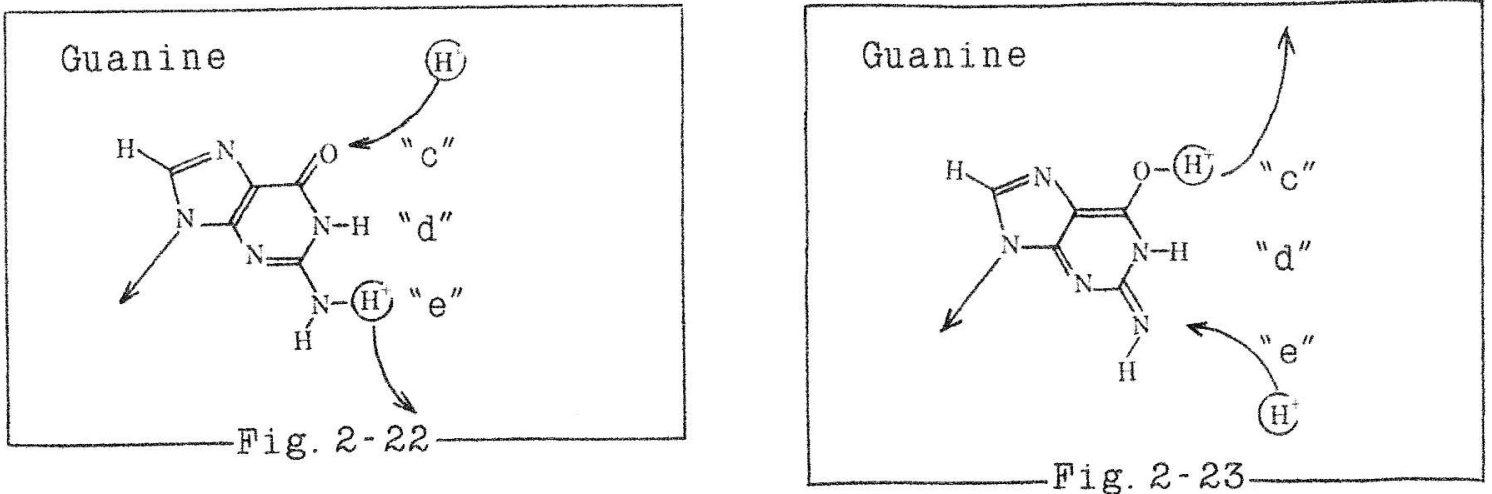

Also the reverse will be possible. At Fig.2-23, provided an independent hydrogen ion combines to the nitrogen of the position "e", the hydrogen of the position "c" will separate as an ion. Thus the position of hydrogen changes from "c" to "e".

\section{(4)Partition of hydrogen bond between guanine and cytosine in DNA}

As already known, guanine and cytosine combine by hydrogen bond in three points, "c", "d" and "e", as Fig.2-24. The mechanism that hydrogen bond parts will be hypothesized as the followings. 


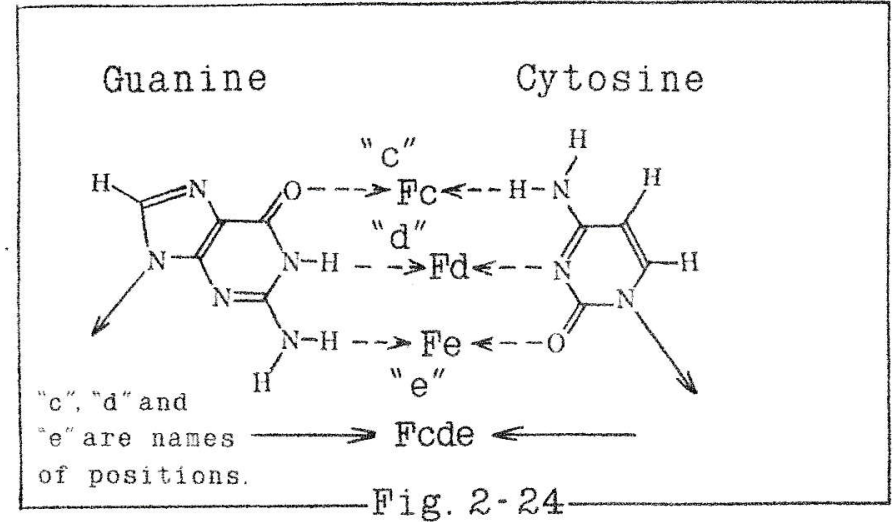

In Fig.2-25, as a free hydrogen ion approaches to the oxygen of guanine in the position "c" attracted electrically, the free hydrogen ion will join to the oxygen of guanine in the position "c", and the hydrogen in the position "e" will leave guanine as an ion. It is possible to think that a tautomer has this function because it has two patterns that the positions of hydrogen are different.

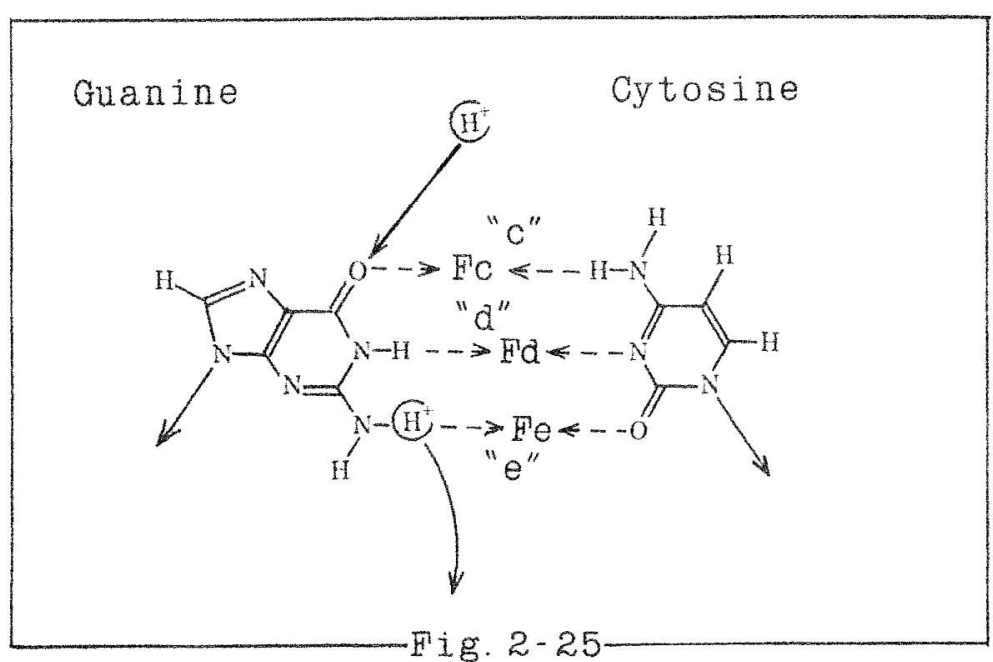

With the result of this tautomeric shift, their relation becomes as Fig.2-26.

The sum of repellent force $\triangle \mathrm{Fc}$ " and $\triangle \mathrm{Fe}$ " may be greater than attractive force $\mathrm{Fd}$. So the total force is repulsion $\triangle \mathrm{F}$ cde".

Therefore hydrogen bond between guanine and cytosine will break.

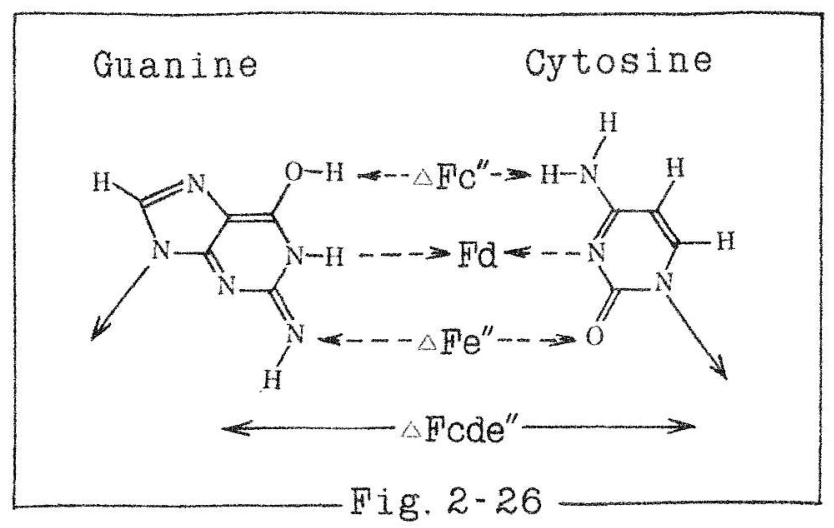




\section{(5)Summary and illustration}

The foregoing investigation is summarized and illustrated as the followings.(Fig.2-2-7)

(1) In DNA, cytosine and guanine combine each other by hydrogen bond.

(2) Provided a free hydrogen ion enters to cytosine in position " $\mathrm{e}$ ", the hydrogen in position " $c$ " will part from cytosine as an ion.

(3) As its result, cytosine and guanine will come to repel in the position "c" and "e". The magnitude of repulsion is greater than the attractive force in the position " $d$ ". Therefore cytosine and guanine will separate.

(4) Similarly, tautomeric shift occurs in guanine, then guanine and cytosine repel and separate.

(5) Through these processes Hydrogen bond between cytosine and guanine will separate. Double helix of DNA gets loose by the function of a hydrogen ion as a DNA cutter. When DNA double helix has completed to separate, cytosine and

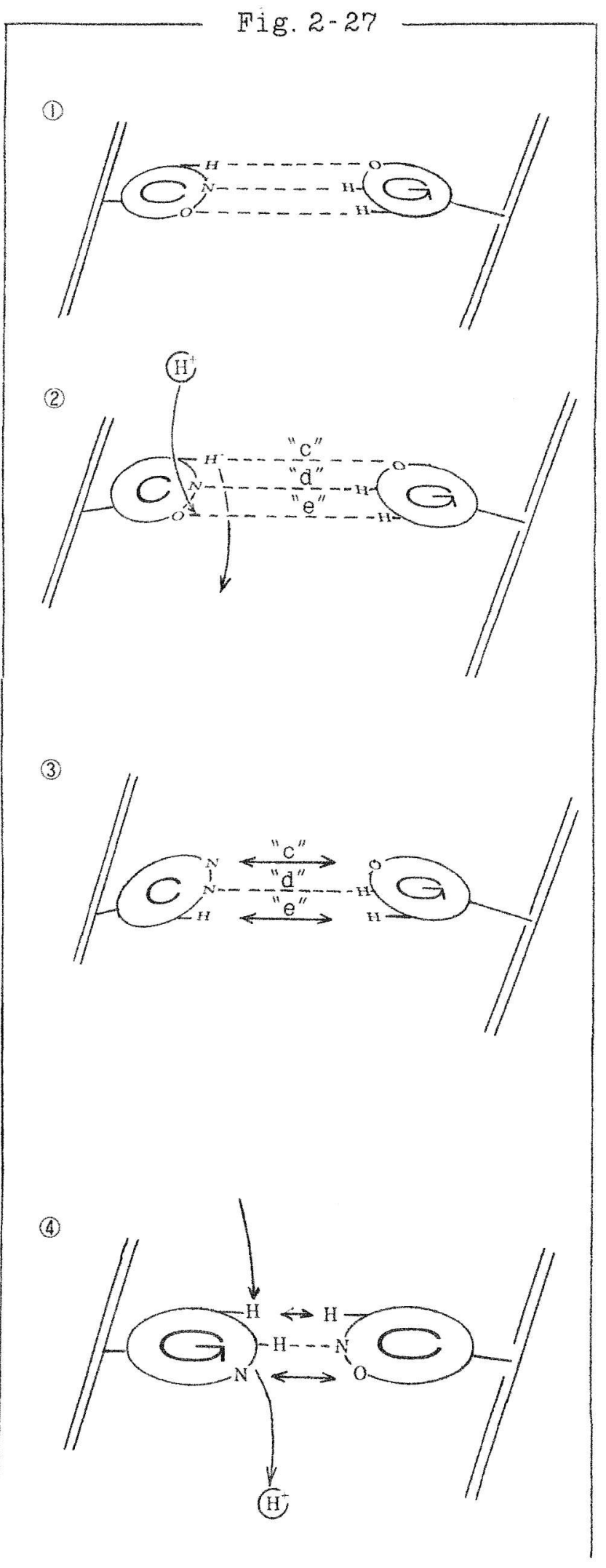


guanine are left as it had shifted tautomerically. Its recoverable system will be evolved at chapter 4 section 4 .
3. Separation of DNA

Fig. $2 \cdot 28$ is the summary that double helix of DNA, containing not only guanine and cytosine but also thymine and adenine, is separated by hydrogen ions.
(5)

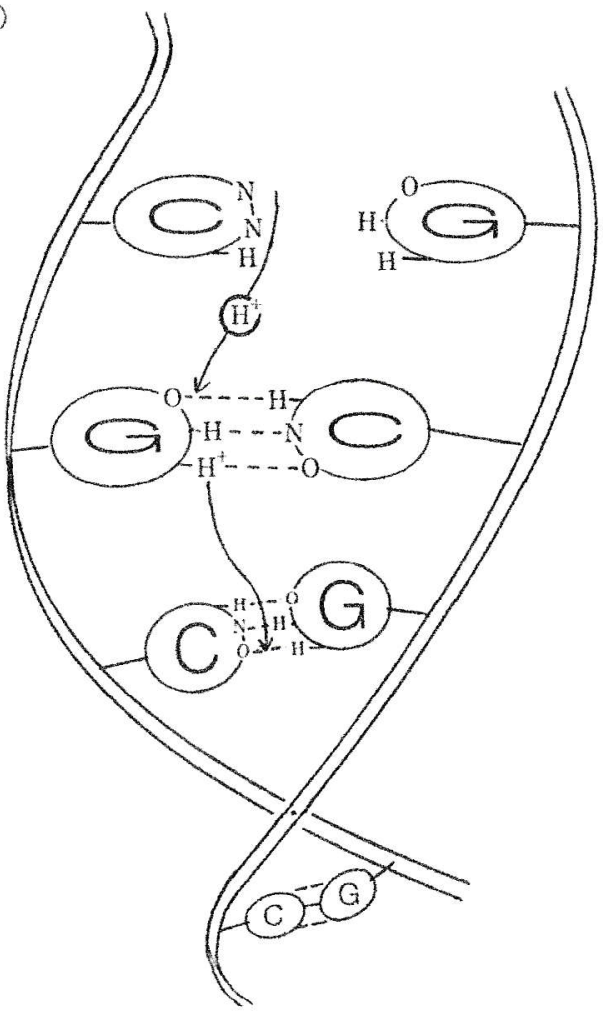

Fig. $2-28$

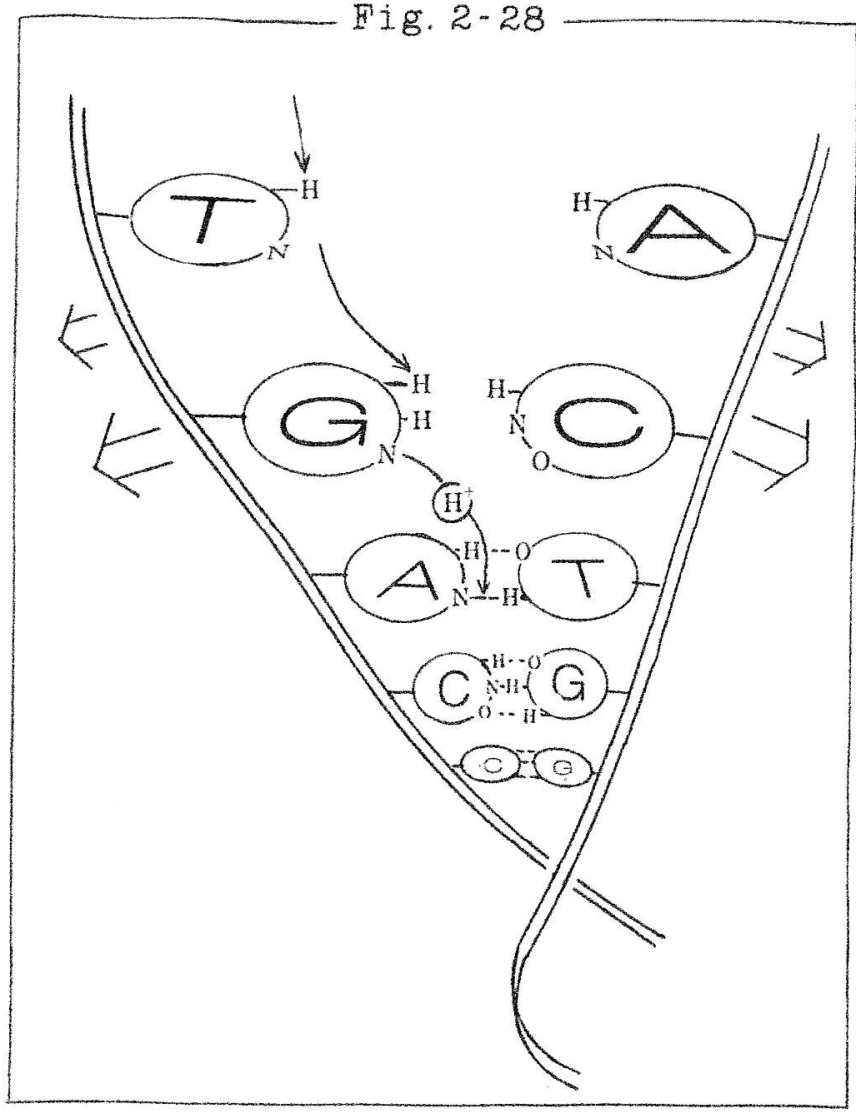




\section{Tautomerically shifted DNA is recovered by RNA}

Here I must set up one hypothesis that the replacement of positions of hydrogen by tautomeric shift occurs at only one side of double helix. Because it can be thought that it is related to the fact that the processes of DNA replication are different in the lagging strand and in the leading strand at the processes of replication of divided DNA.

It can be thought that the strand changed the position of hydrogen by tautomeric shift is lagging strand and the strand unchanged is leading strand.

In the leading strand, base pairing is composed immediately by bonding complementarily. But in lagging strand, at first RNA primer bonds with bases of lagging strand in each Okazaki fragment, later bases make pairs complementarily, and DNA double helix is completed. Why in lagging strand bases bond with RNA primer at first? Because it can be thought that tautomerically shifted bases are recovered to the patterns before the tautomeric shift by bonding with RNA primer. Its mechanism can be explain as the followings.

\section{(1)Tautomerically shifted base of DNA bonds with RNA}

The division of hydrogen bond of DNA is accompanied by the tautomeric shift in bases. Their results are Fig.2-29.

The shifted bases of DNA will be able to bond with bases of RNA primer as the followings.

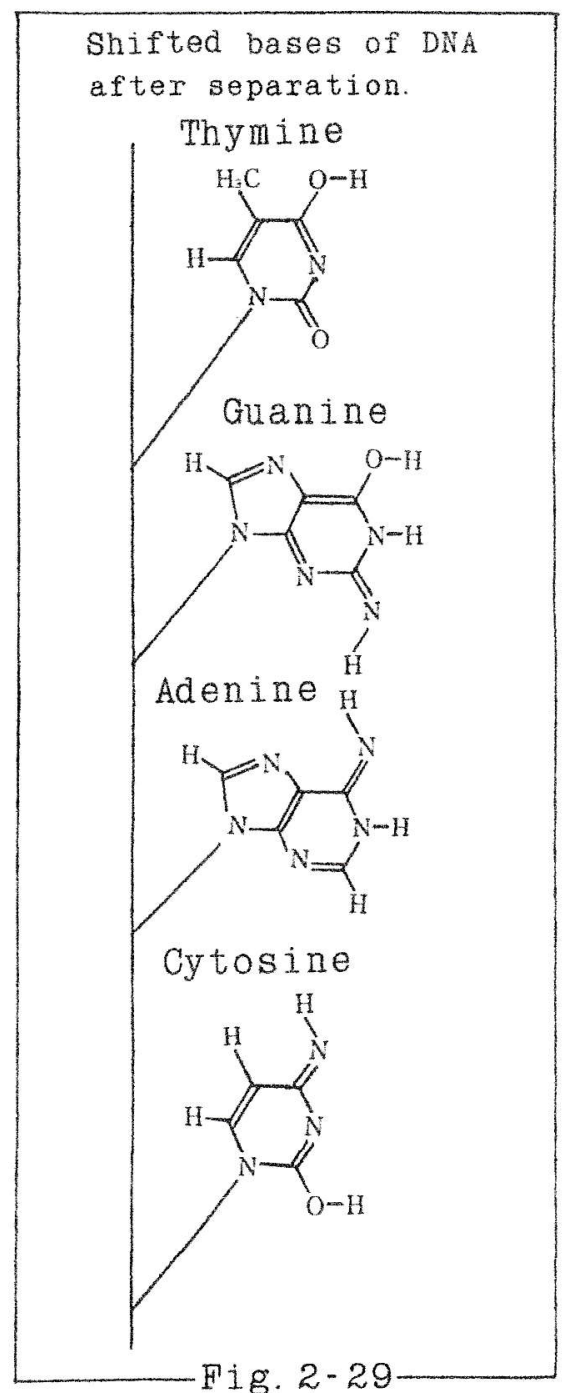


Tautomerically shifted thymine of DNA has possibility to bond with adenine of RNA primer as Fig.2-30. Here, adenine of RNA primer bonds with shifted thymine inside out comparing with adenine's situation in DNA double helix.

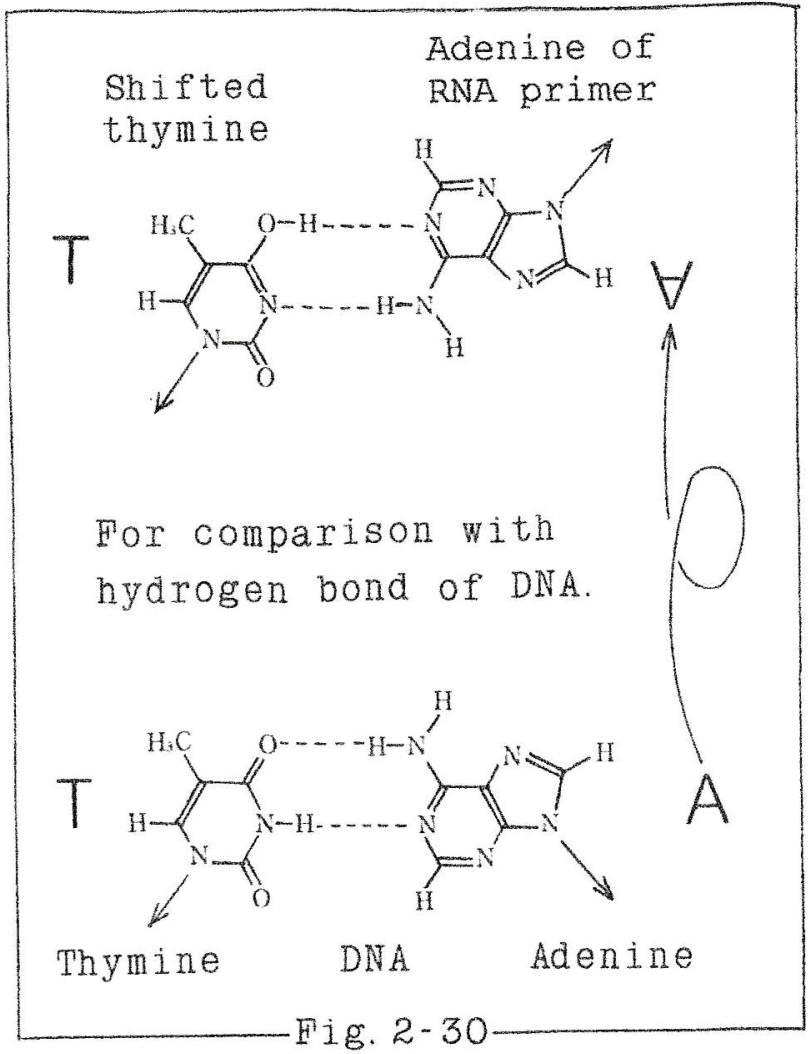

Similarly guanine that was shifted tautomerically for DNA separation can bond with cytosine of RNA primer as Fig.2-31. Cytosine of RNA primer is inside out in situational relation compared with the bonding situation in DNA.

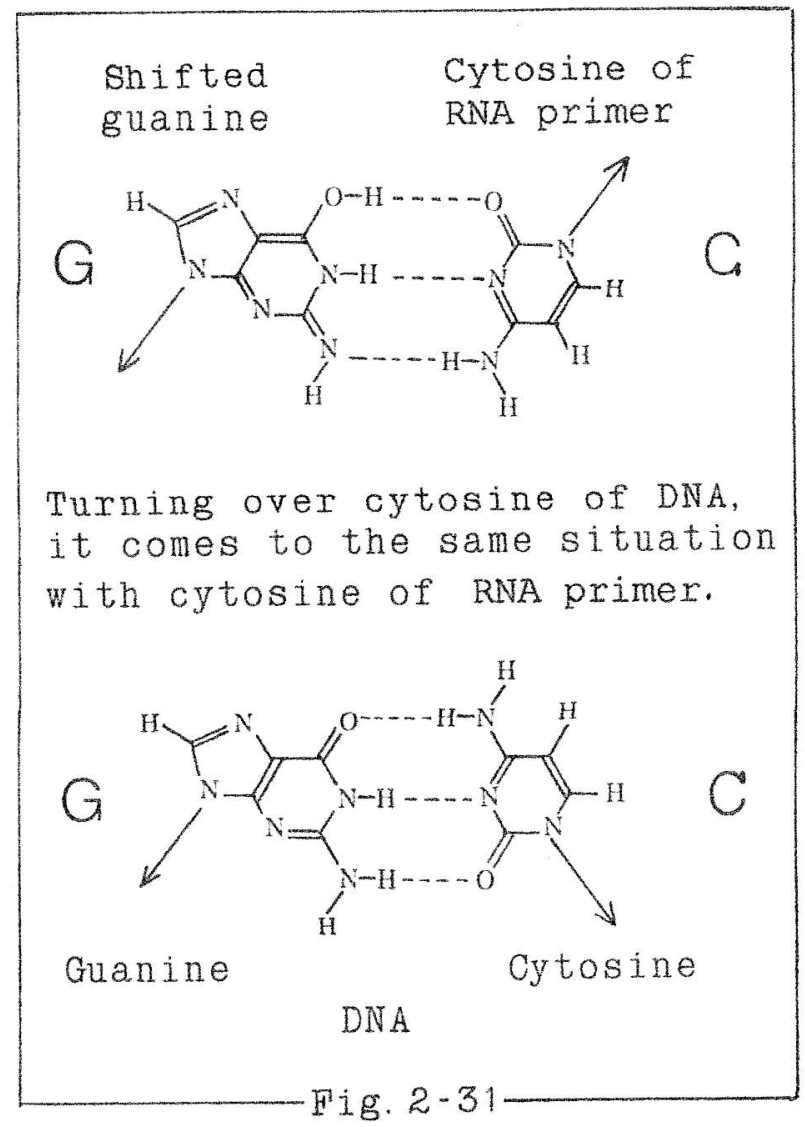


Adenine shifted tautomerically will be able to bond with uracil of RNA primer as Fig.2*32.

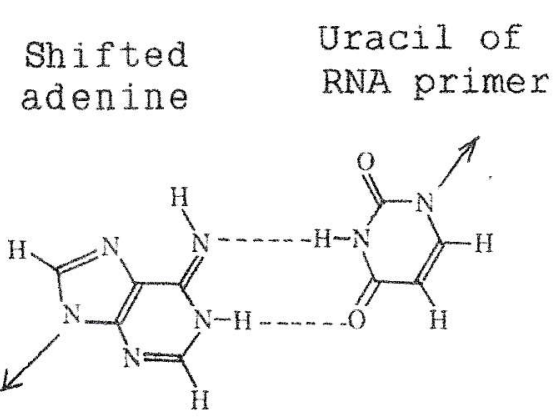

Fig. $2-32$

Shifted cytosine bonds with guanine of RNA primer as Fig. $2 \cdot 33$. The situation of guanine is inside out in comparison with that in DNA.

Shifted

cytosine of Guanine of divided DNA RNA primer

C

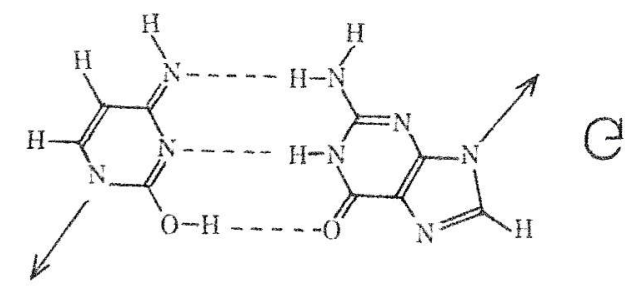

For comparison with

the situation of guanine in DNA.

C

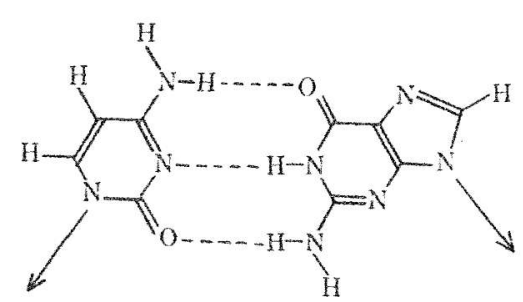<smiles>[SiH3]</smiles>

Cytosine

DNA 
Fig.2-34 is the illustration summarized that shifted DNA bonds with RNA primer.

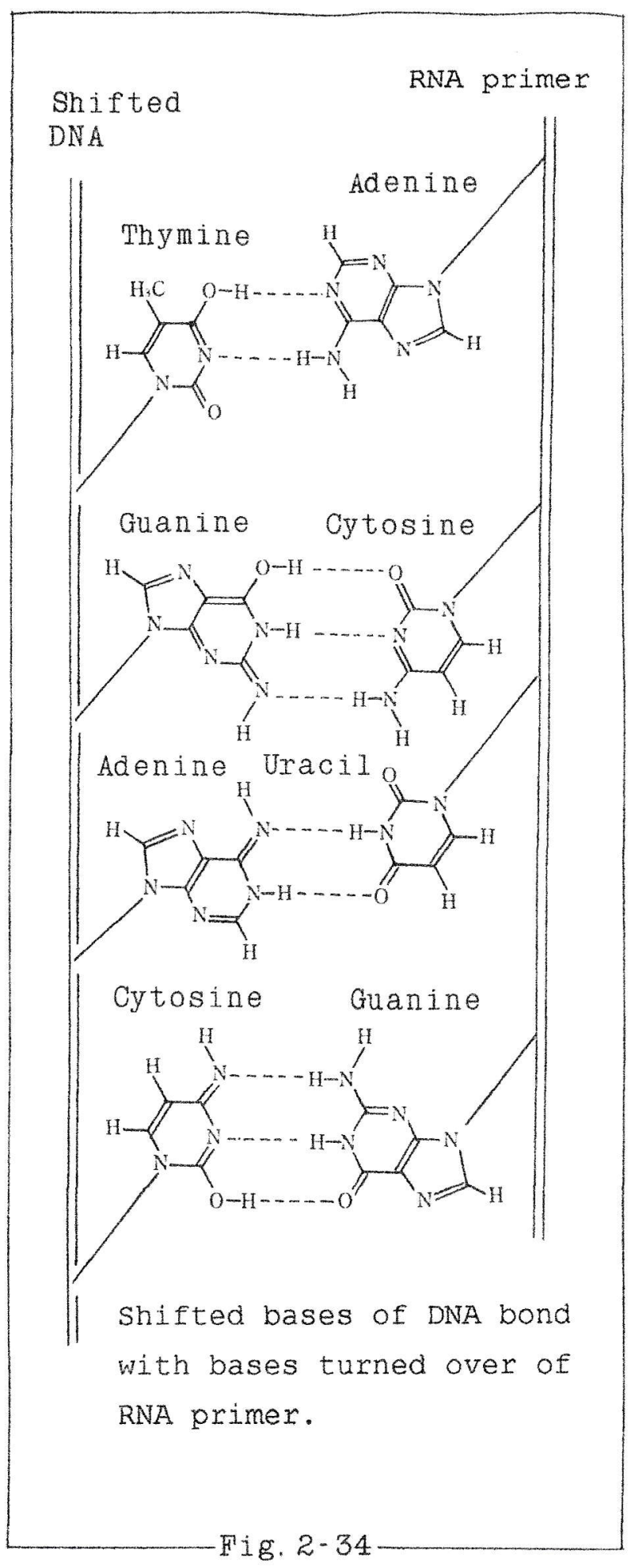

Fig. $2-34$

\section{(2)The recovery of bases of DNA that were shifted tautomerically}

In the next time bonded bases of DNA and RNA primer will separate. In this process, the hydrogen ion plays a role to cut the DNA-RNA bond cooperating with the characteristic of a base as a tautomer. The mechanism can be hypothesized as the followings. 
(1) Thymine and adenine

In Fig.2-35 provided a free hydrogen ion enters to the position " $b$ " and combines with the nitrogen of DNA, the hydrogen of thymine in the position "a" leaves there as an ion. In this way the hydrogen changes its position. This change is the reverse to the case that DNA double helix divides. In this time, the thymine recovers the situation of hydrogen position before DNA separation. In the result of this tautomeric shift, thymine of DNA and adenine of RNA primer will repel each other as Fig.2-36.
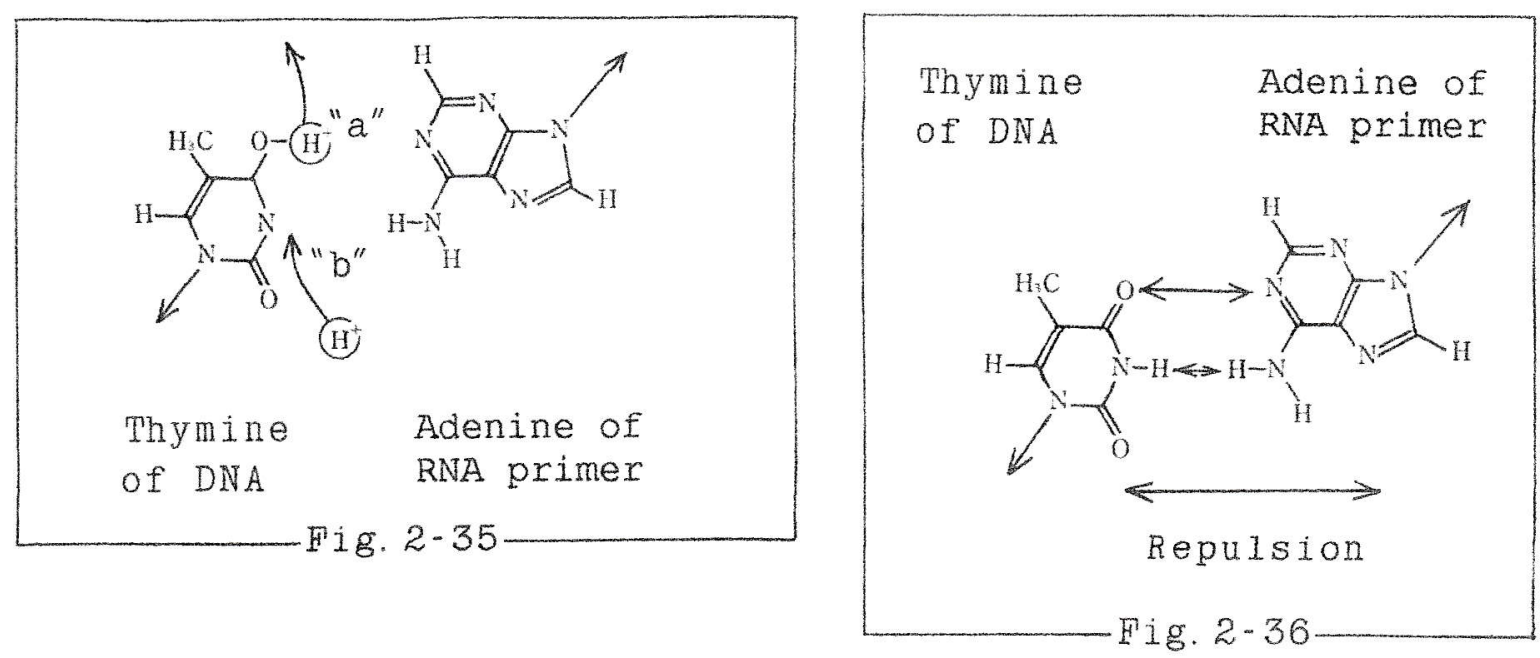

(2) Guanine and cytosine In Fig. 2-37, when a free hydrogen ion sits in the position " $e$ " of guanine of DNA, the hydrogen of guanine in the position "c" leaves there as an ion.

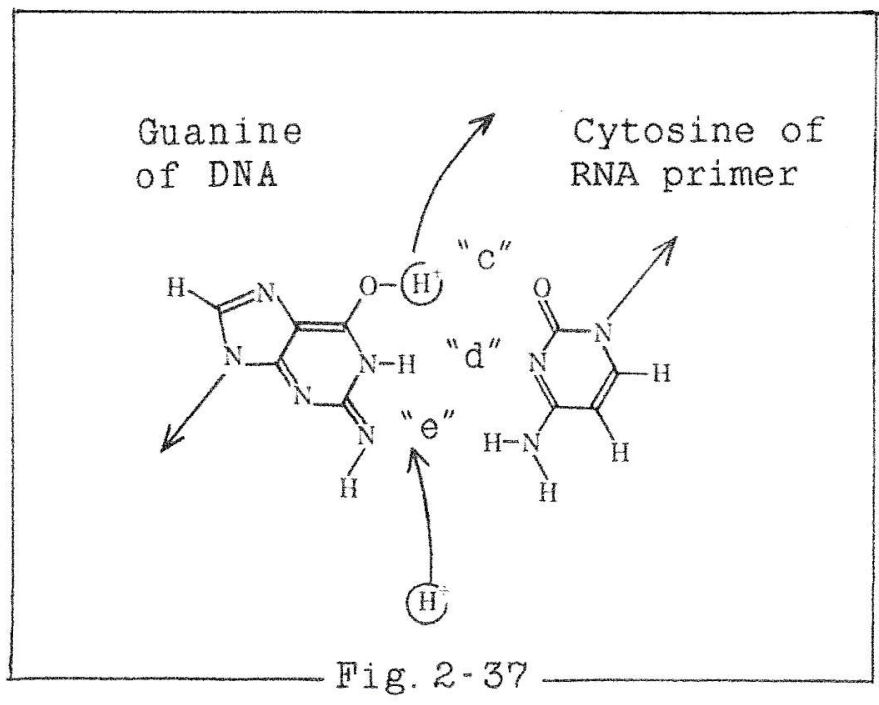

Then the relation of guanine of DNA and cytosine of RNA primer becomes as Fig.2-38. Here the resultant force is repulsion because guanine and cytosine repel in two points and attract in one point. Therefore the hydrogen bond between guanine of DNA and cytosine of RNA primer breaks and these two bases will separate out. 
Through this process, the guanine that has shifted tautomerically in DNA separation returns to the original situation composing the double helix.
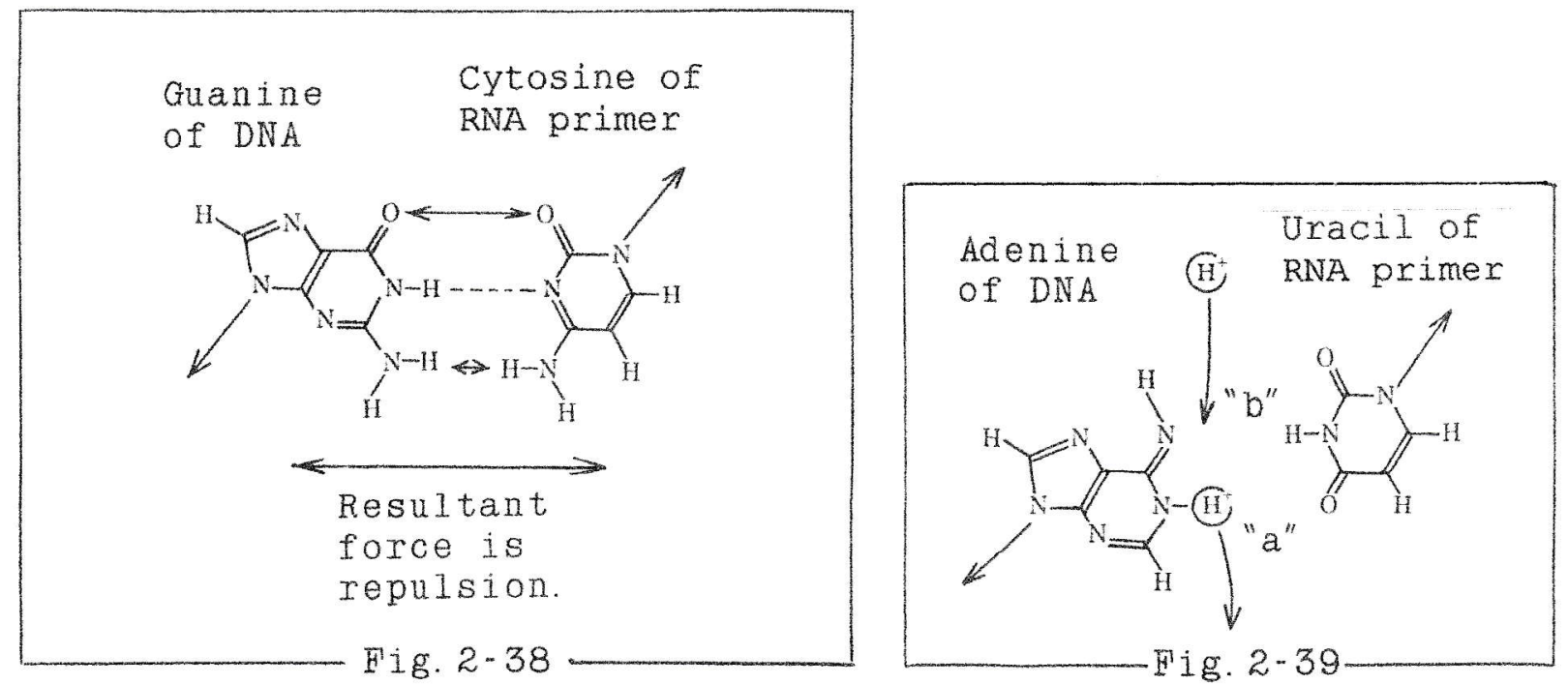

(3) Adenine and uracil

In Fig.2-39, when a free hydrogen ion combines with the nitrogen of adenine in the position " $b$ ", the hydrogen in the position " $a$ " will leave there as an ion. Then, as Fig. 2-40 adenine and uracil will repel because of confrontation of the same electric charges. In this process, tautomerically shifted adenine recovers to the situation before DNA separation.

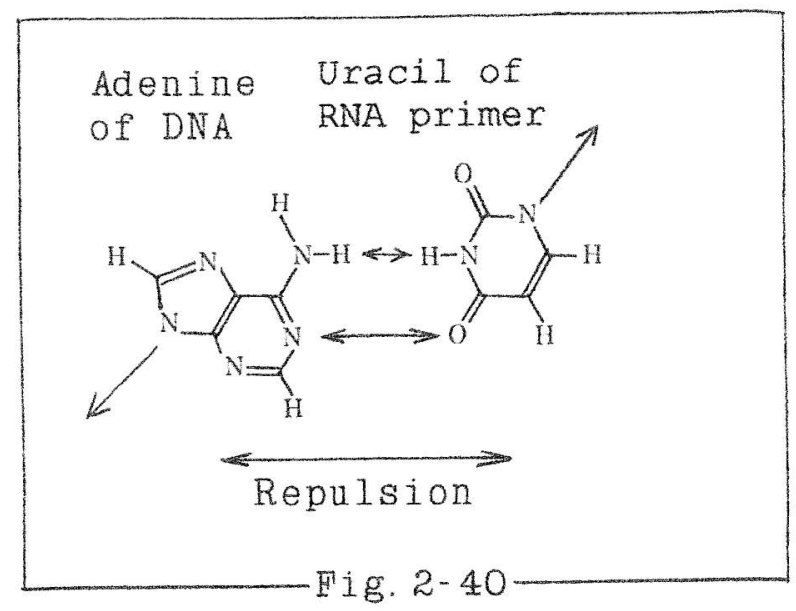

(4) Cytosine and guanine

Fig.2-41 is the illustration that the hydrogen's position of cytosine changes from " $c$ " to " $\mathrm{e}$ " by a tautomeric shift. Its result is Fig.2-42. Cytosine of DNA returns to the structure before DNA

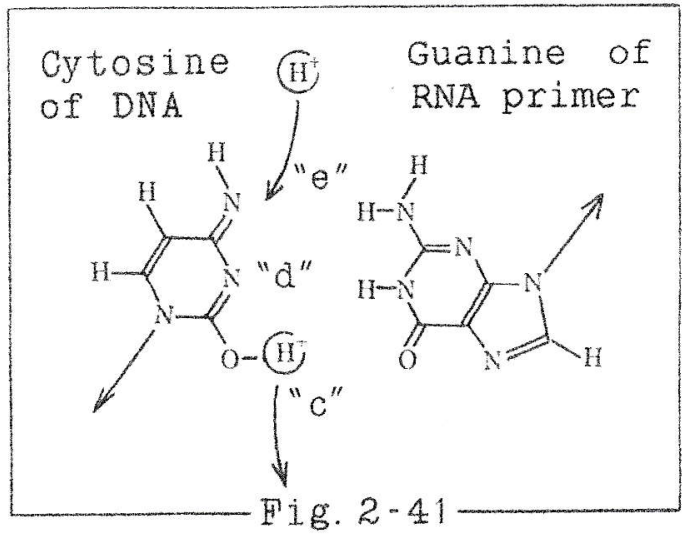


separation. And the resultant force between cytosine and guanine becomes repulsion. Thus, these two bases will come to divide.

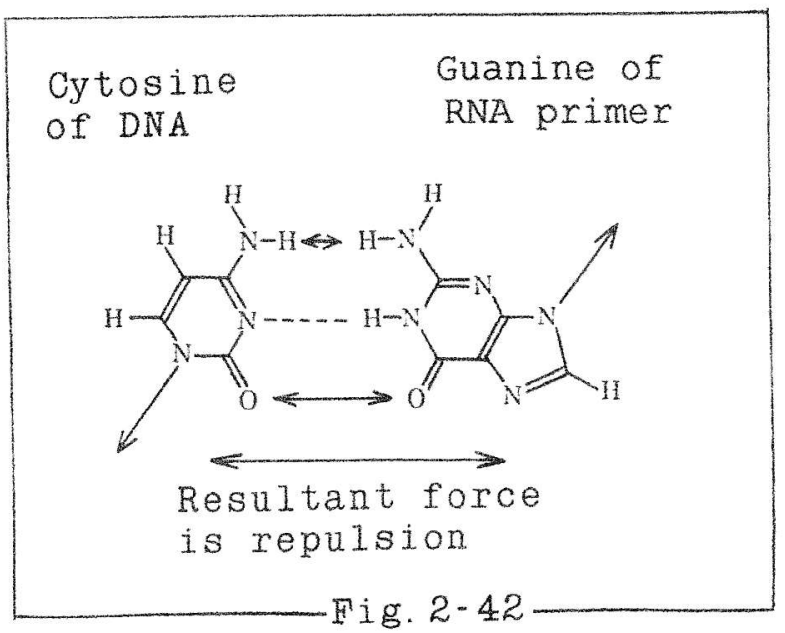

Through these processes, bases of DNA change the positions of hydrogen. As its result, the form of each base of DNA will recover to the situation before separation of DNA double helix. And bonding between DNA and RNA primer will divide(Fig.2-43). These processes explain why the DNA replication is necessary the bonding with RNA before forming new DNA strand by complementary bonding with bases. 


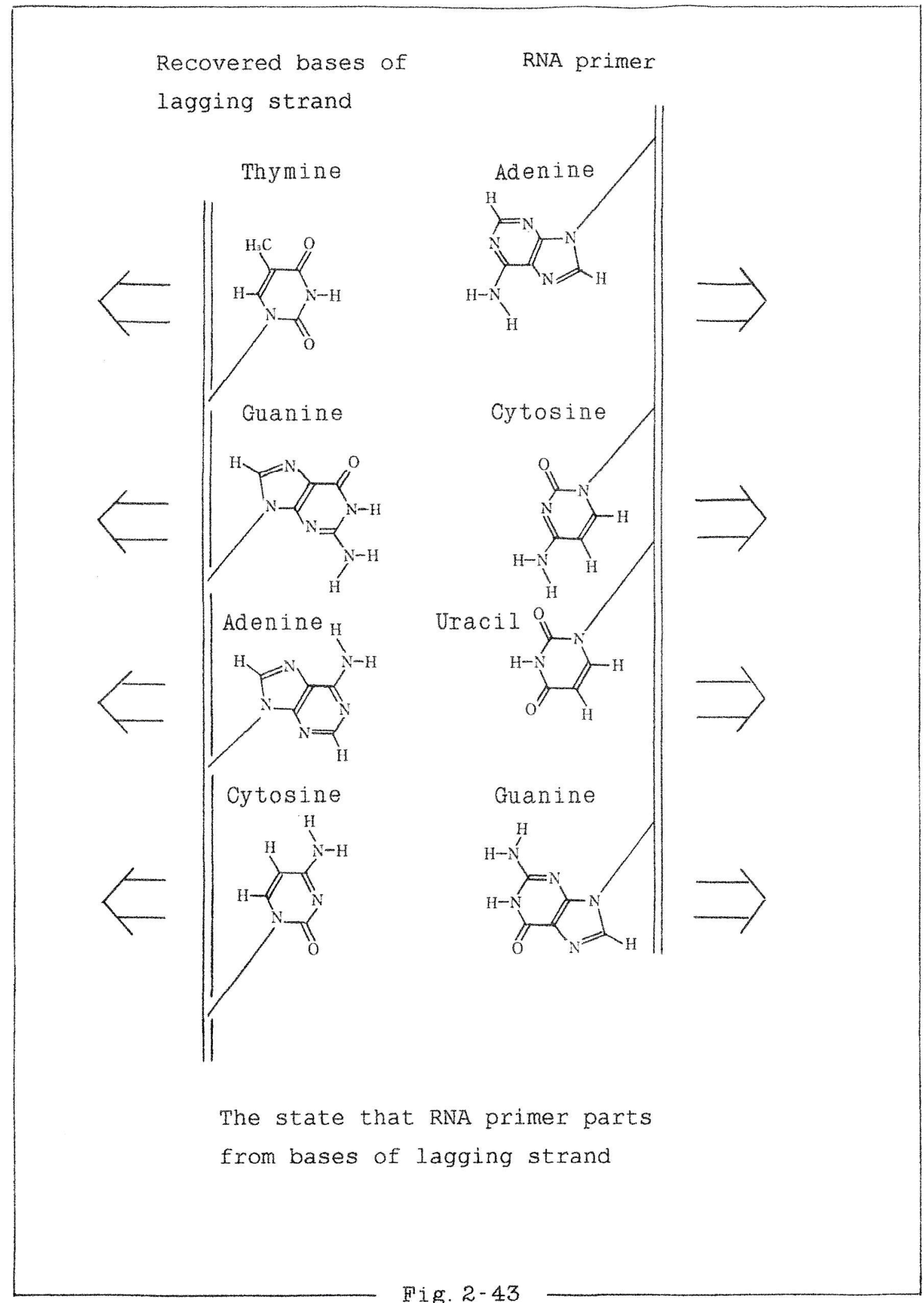

Fig. $2-43$ 
(3)It is possible that the parts of bases not bonded with RNA primers recover from its tautomeric shift by delivering hydrogen ions into bases

There is a issue left how bases not bonded with RNA primer recover its tautomeric shifts.

From outside of bases a hydrogen ion bonds with a base and another hydrogen of the base leaves from the base as a hydrogen ion. Also in the parts of bases that RNA primers do not bond, this replacement of hydrogen's position can occur.

Therefore it is possible that tautomerically shifted bases recover by delivering a hydrogen ion from a base to a base in the parts of bases of lagging strand that RNA primers do not bond. (Fig.2-44)

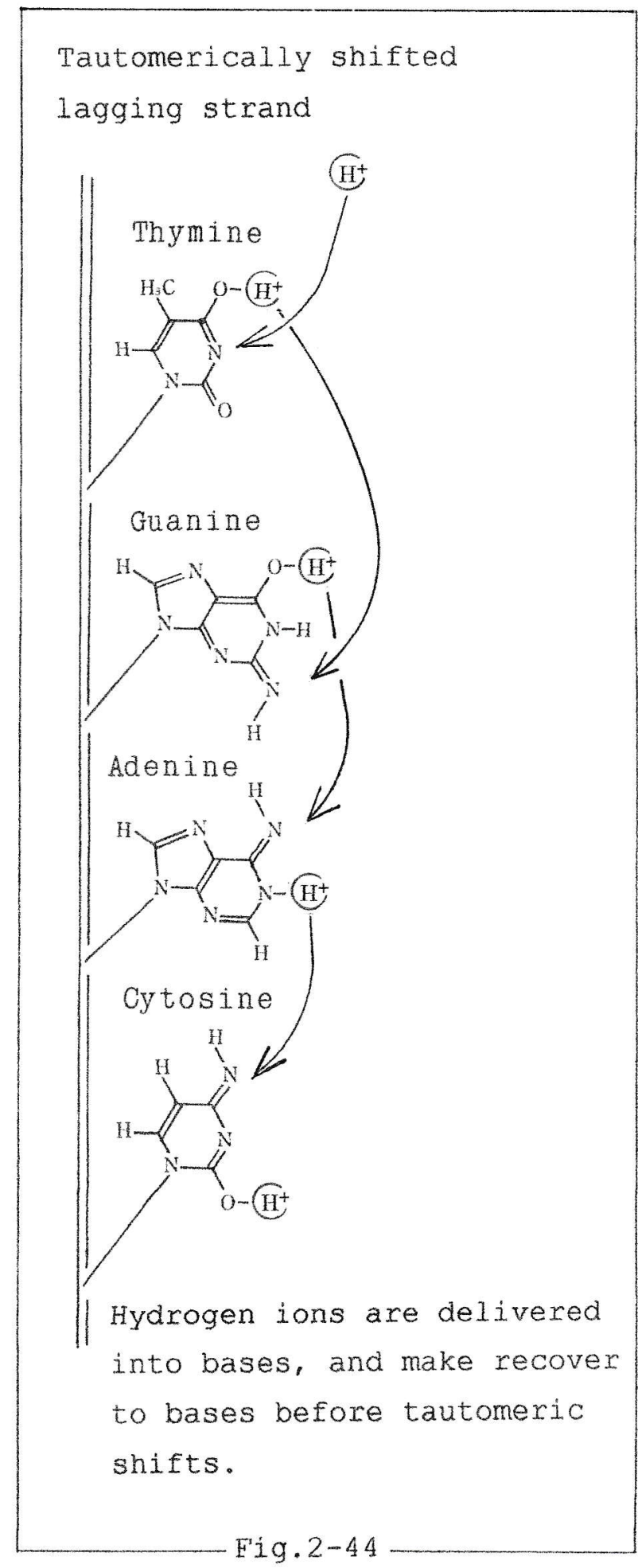


(4)It is natural to think that RNA primer does not bond to leading strand The purpose that RNA primer bonds with a single-stranded of DNA is a recovery from a tautomeric shift. But this thought cannot explain the meaning of RNA primer's bonding with leading strand that a tautomeric shift does not occur. Therefore it is natural to think that leading strand bonds with bases directly and DNA is replicated without RNA primer's bonding. 


\section{(5)Summary by illustration}

Fig.2-45 is a summary of the whole of chapter 2 .

A hydrogen ion

causes tautomeric

shift, and DNA divides.
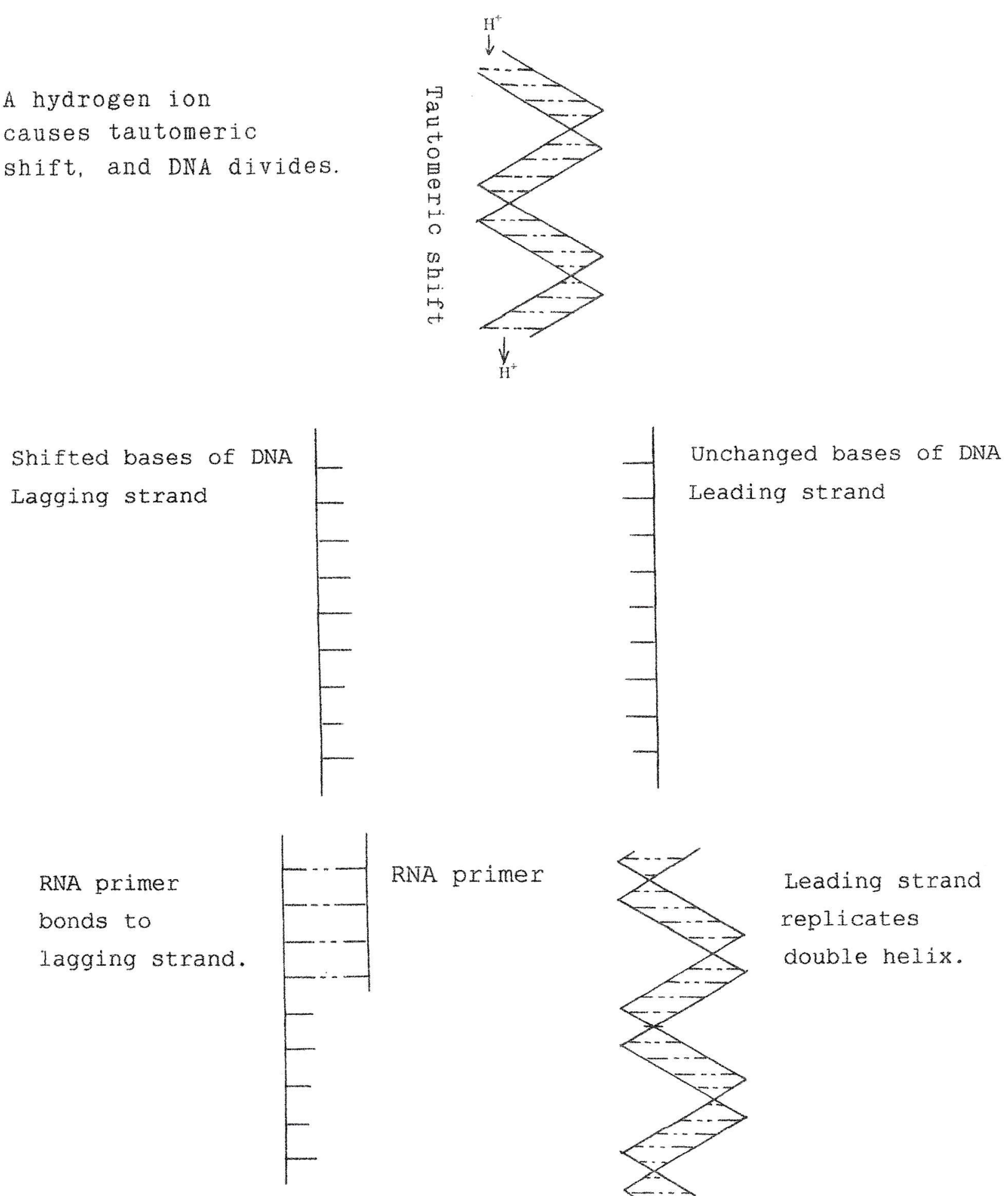

RNA primer

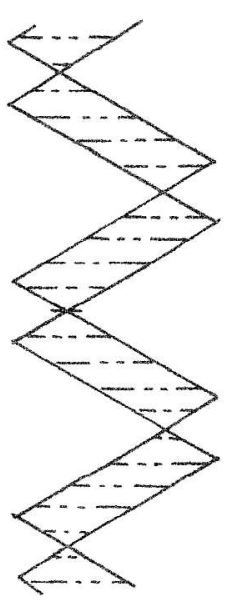

Leading strand

replicates

double helix. 
Lagging strand

of DNA

A hydrogen ion

causes tautomeric

to lagging strand and

divides DNA-RNA bonding.

A hydrogen ion rolls on bases of lagging strand, and make to recover to the forms before tautomeric shifts.
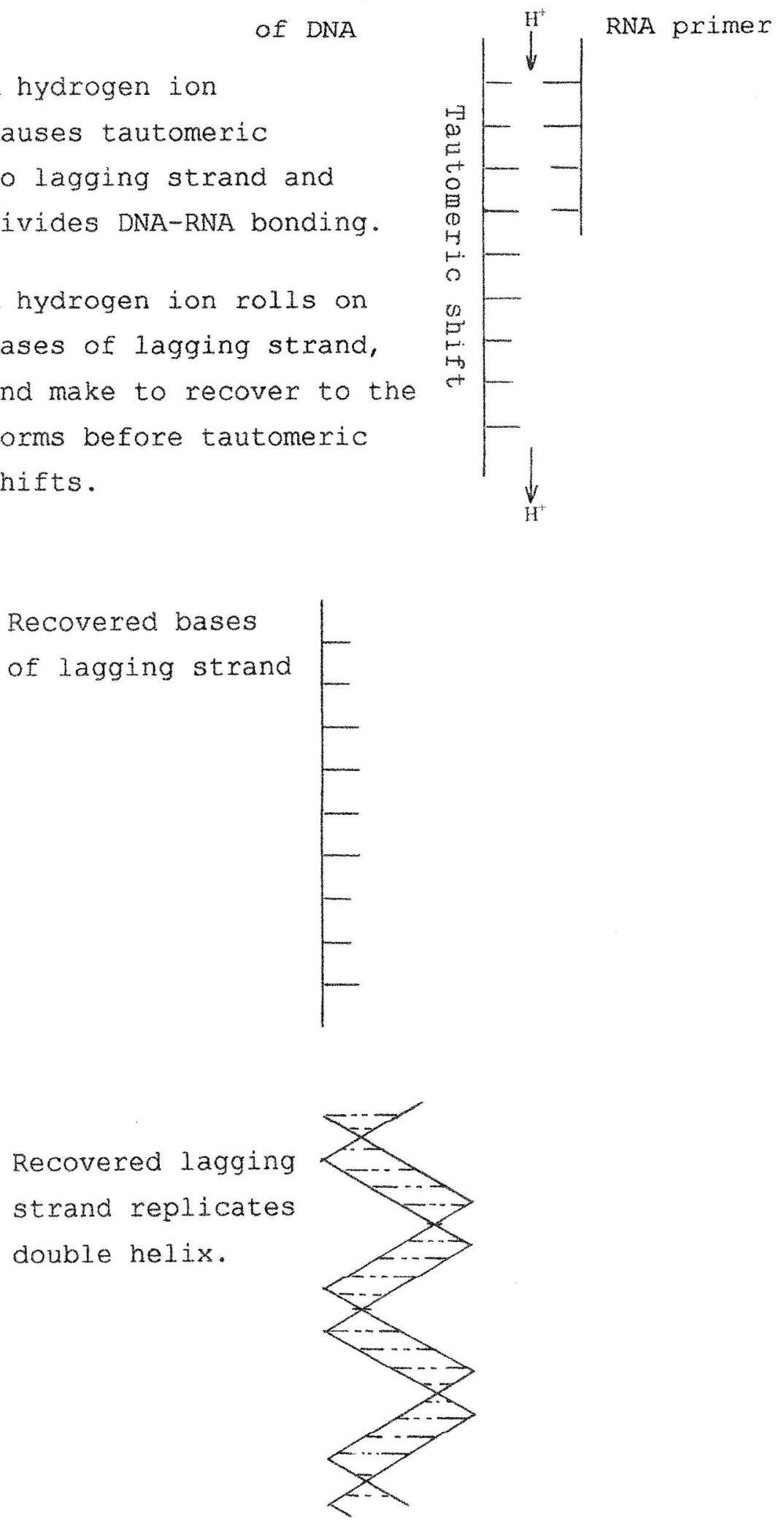


\section{Chapter 3}

\section{The rate of cell division is decided by a quantity of hydrogen ions}

1. Redefine the process of cell cycle regarding to a quantity of hydrogen ions (1)Subdivide cell cycle

Here cell cycle is redefined as the followings.

(1) The period of the first gap (G1)

G1 can be further divided into two.

(1)-1 The period of the variable first gap (G1v)

(1) -2 The period of the fixed first gap (G1f)

(2) The period of DNA replication (S)

(3) The period of the second gap (G2)

(4) The period of division (M)

Regarding the function of hydrogen ions in a cell, the period of DNA replication (S) can be divided into more two sections. One is the period when DNA cutting and replication are taking place. This period can be named the first period of DNA replication (S1). Another is the period when divided DNA is performing only replication, DNA cutting already ended. This period can be named the second period of DNA replication ( $\mathrm{S} 2)$.

Therefore cell cycle can be divided into six periods as follows.
(1) $-1 ; \mathrm{G} 1 \mathrm{v}$
(1). 2 ; G1f
(2) $-1 ; \mathrm{S} 1$
(2) $-2 ; \mathrm{S} 2$
(3) ; G2
(4) ; M

(2)Movement of a quantity of hydrogen ions at each period of cell cycle

(1) 1 The period of the variable first gap (G1v)

At this period a cell is decided whether it moves forward to cell division or not, because hydrogen ions begin to cut DNA when hydrogen ions in a cell reach to a certain level.

This value of the level is named "the level of hydrogen ions to start cell division" and symbolizes "hs". The period of the variable first gap (G1v) is the process that hydrogen ions in a cell increase to "hs", the value to start cell division. And when the value of hydrogen ions reaches to hs, the cell starts DNA cutting with hydrogen ions. If they do not reach to hs, the cell goes on stillness. The time of this period changes according to the rate of generating hydrogen ions. The quantity of hydrogen ions generated in this period is 
symbolized "hv".

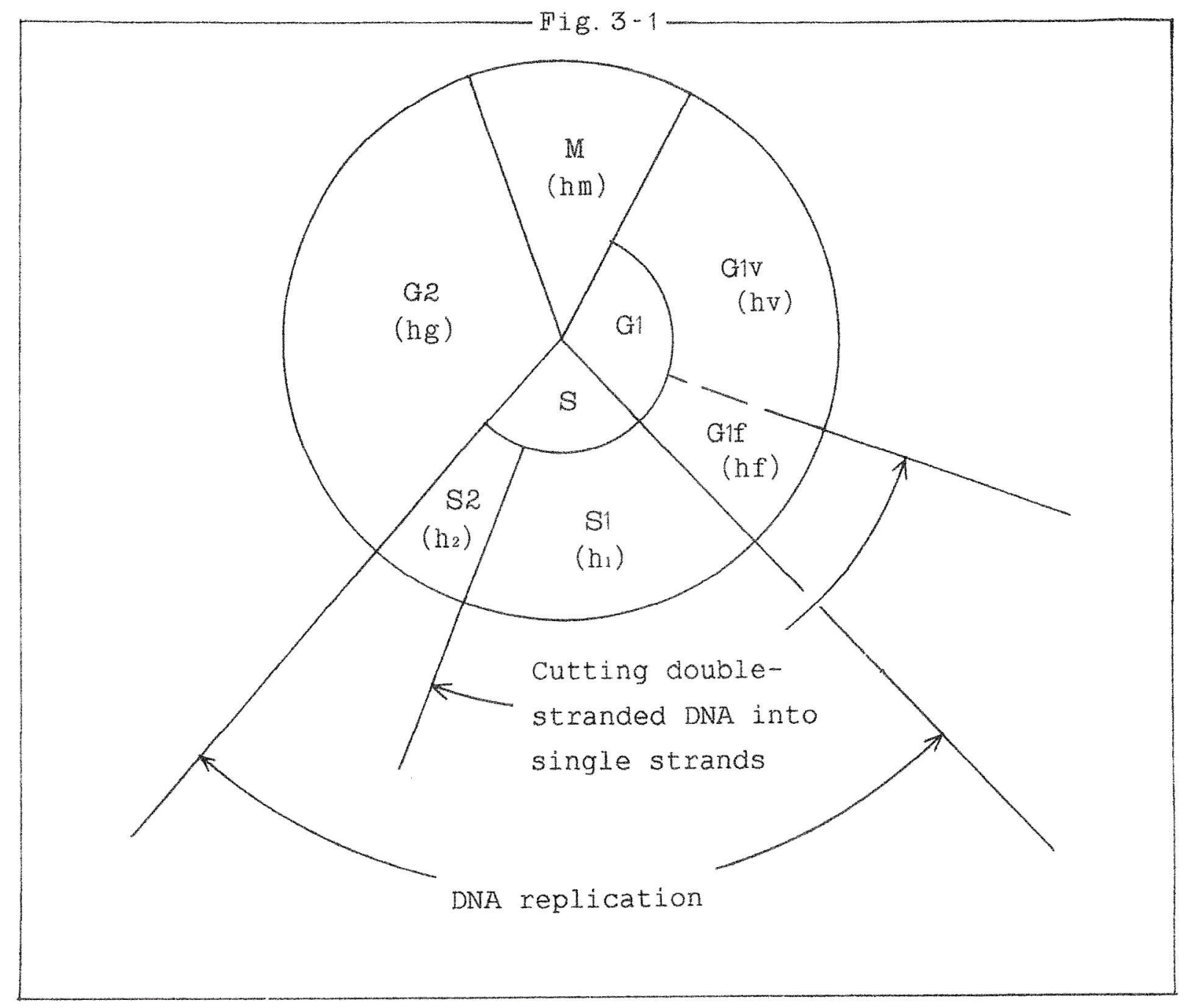

(1)-2 The period of the fixed first gap (G1f)

The cell that its value of hydrogen ions has reached to the level of starting cell division, "hs" begins to cut DNA. After that, severed DNA begins to replicate. It will be natural that DNA replication occurs not soon after DNA cutting rather than an immediate start. This period is the stage that DNA cutting occurs but DNA replication does not yet.

The length of this period is influenced by a quantity of hydrogen ions.

The quantity that are generated in this period is expressed as "hf".

(2) 1 The period of the first DNA replication (S1)

DNA severed in the G1f period begins to replicate. Simultaneously DNA cutting goes on in other side.

The time of this period can change by the quantity of hydrogen ions, because much more hydrogen ions urge a rate of DNA cutting much more.

The hydrogen ions generated in this period are symbolized as $\mathrm{h} 1$.

(2) -2 The period of the second DNA replication (S2) 
In the period of G1f, it is thought that there is a time lag between DNA cutting and DNA replication. Its reverse phenomenon appears in this period, S2. That is, DNA cutting has already ended but DNA replication is going on. At the end of this period, DNA replication completes.

The length of this period is not dependent on a quantity of hydrogen ions.

The quantity of hydrogen ions generated in this period is symbolized as h2.

(3) The period of second gap (G2)

This period is the step that chromosomes condense and turn to the period of division. Therefore the length of this period is not influenced by hydrogen ions.

The quantity of hydrogen ions generated in this period is named hg.

(4) The period of division (M)

In this period, a nucleus and a cytoplasm divide, and a cell divide into two daughter-cells. Hydrogen ions do not have an influence on the length of this period.

The quantity of hydrogen ions generated in this period is symbolized as $\mathrm{hm}$.

(3) Movement of a quantity of hydrogen ions at cell cycle

$\Theta$ is the aggregate of hydrogen ions generated in each period of cell cycle, and can be indicated as followings.

$$
\Theta=h v+h f+h 1+h 2+h g+h m
$$

The average rate par a time of generating hydrogen ions in one cell cycle is " $g$ ". Then the movement of a quantity of hydrogen ions can be illustrated as the next. (Fig. 3-2)

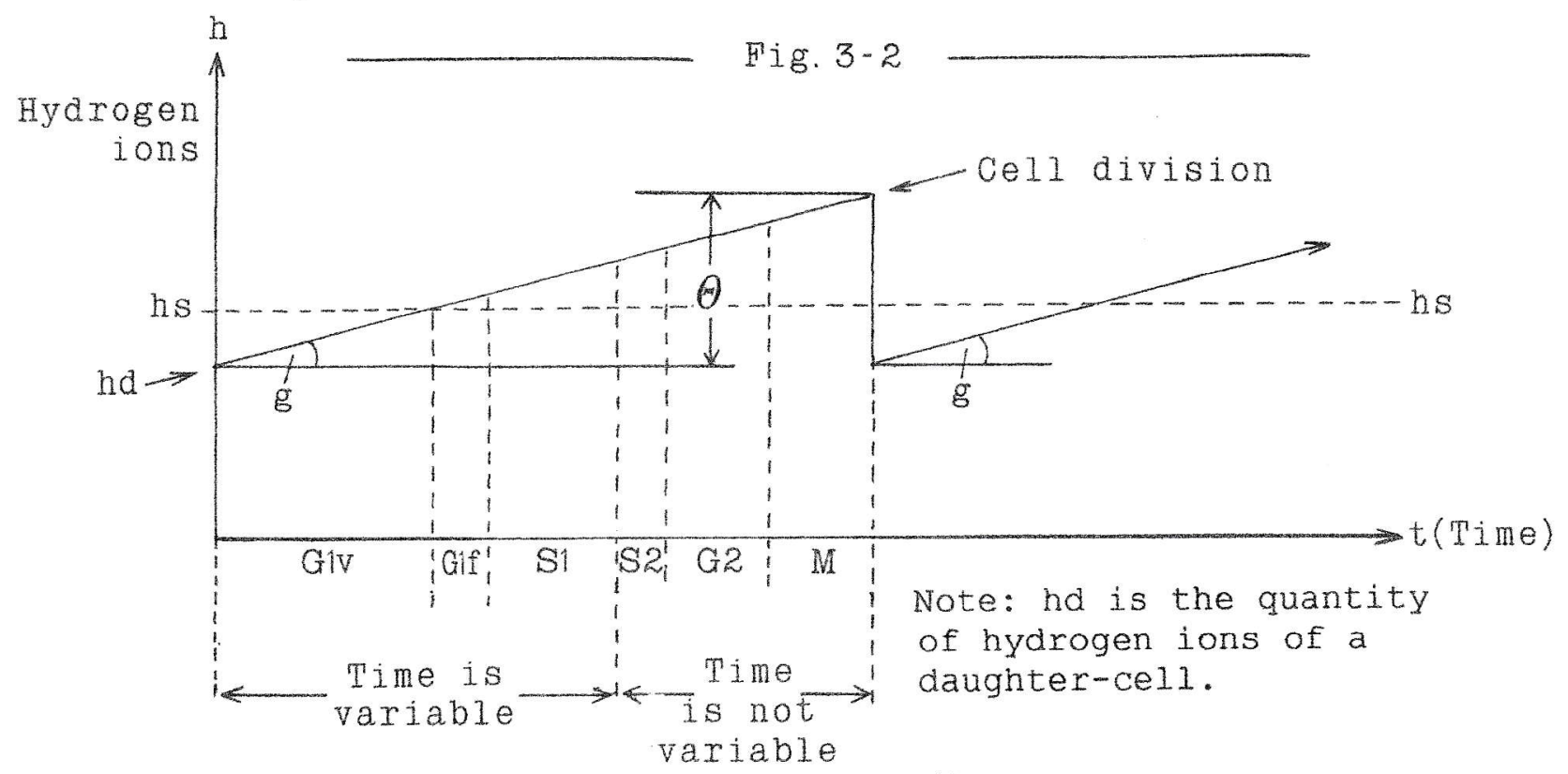

This is the cycle of hydrogen ions in a normal cell. 


\section{The definition of cancer}

(1)Cancer cell is the cell that a quantity of hydrogen ions of daughter-cell right after the cell division already exceeds the level to start the cell division

In the natures of cancer, one of the most fatal nature to the life of a host is that cancer cells continue to divide limitlessly. In reverse expression, if cancer cells do not divide and do not multiply, there are not any influence to the life of a host. The limitless cell division becomes possible when a daughter-cell right after the cell division already has the ability to divide. And such a daughter-cell begins to divide autonomously right after the proceeding cell division without any aids from the outside.

What a daughter-cell already has an ability to divide means that its quantity of hydrogen ions already exceeds the value to start the cell division, hs. This cell can be defined qualitatively as cancer.

\section{(2)Expressing the state of a quantity of hydrogen ions in a cancer cell by a chart}

As indicated in the qualitative definition, a cancer cell already has hydrogen ions beyond the value of hs that the cell division starts. This can be formulated as follows.

$$
\text { hd } \geqq \text { hs }
$$

(hd is a quantity of hydrogen ions of daughter-cell)

In opposition to cancer, a normal cell can be formulated as follows.

$$
\text { hd }<\text { hs }
$$

The movement of hydrogen ions of a cancer cell can be represented graphically as Fig. 3-3.

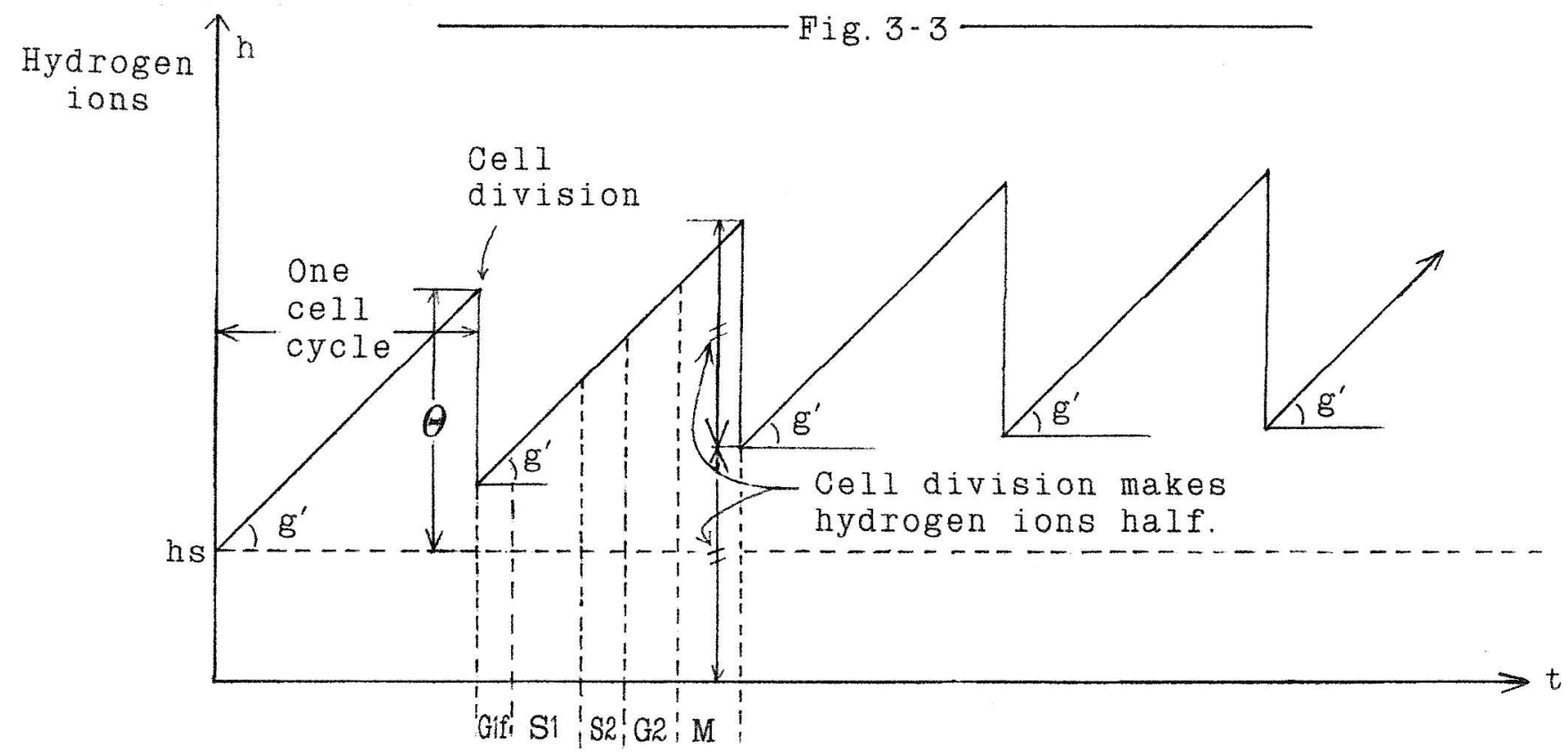


Note $: 1 g^{\prime}$ is a rate of generating hydrogen ions per a time.

2 Supposing that g' is fixed.

3 The G1v does not exist in a cancer cell because of the definition that

a daughter-cell of cancer already exceeds hs.

4 Supposing that one cycle time is fixed.

5 In this case, a quantity of hydrogen ions generating in one cell cycle,

$\Theta$ is more than the value of hydrogen ions of a daughter-cell in that cell cycle.

\section{Chapter 4}

\section{The principle and the practical methods of a treatment for cancer}

\section{A cure for cancer means stopping the cell division of cancer cells}

When $g$ (the rate of generating hydrogen ions) reduces and $\Theta$ (a quantity of hydrogen ions generated in one cell cycle) becomes less than hd (a quantity of hydrogen ions of a daughter-cell at the beginning of the cell cycle (namely $\Theta<$ hd ), hydrogen ions of a cancer cell come to decrease in every cell division. (Refer to Fig. 4-1) Because,

$\mathrm{hd}_{1}$ : hydrogen ions of the daughter-cell at the first cell cycle

$\mathrm{hd}_{2}:$ hydrogen ions of the daughter-cell at the second cell cycle

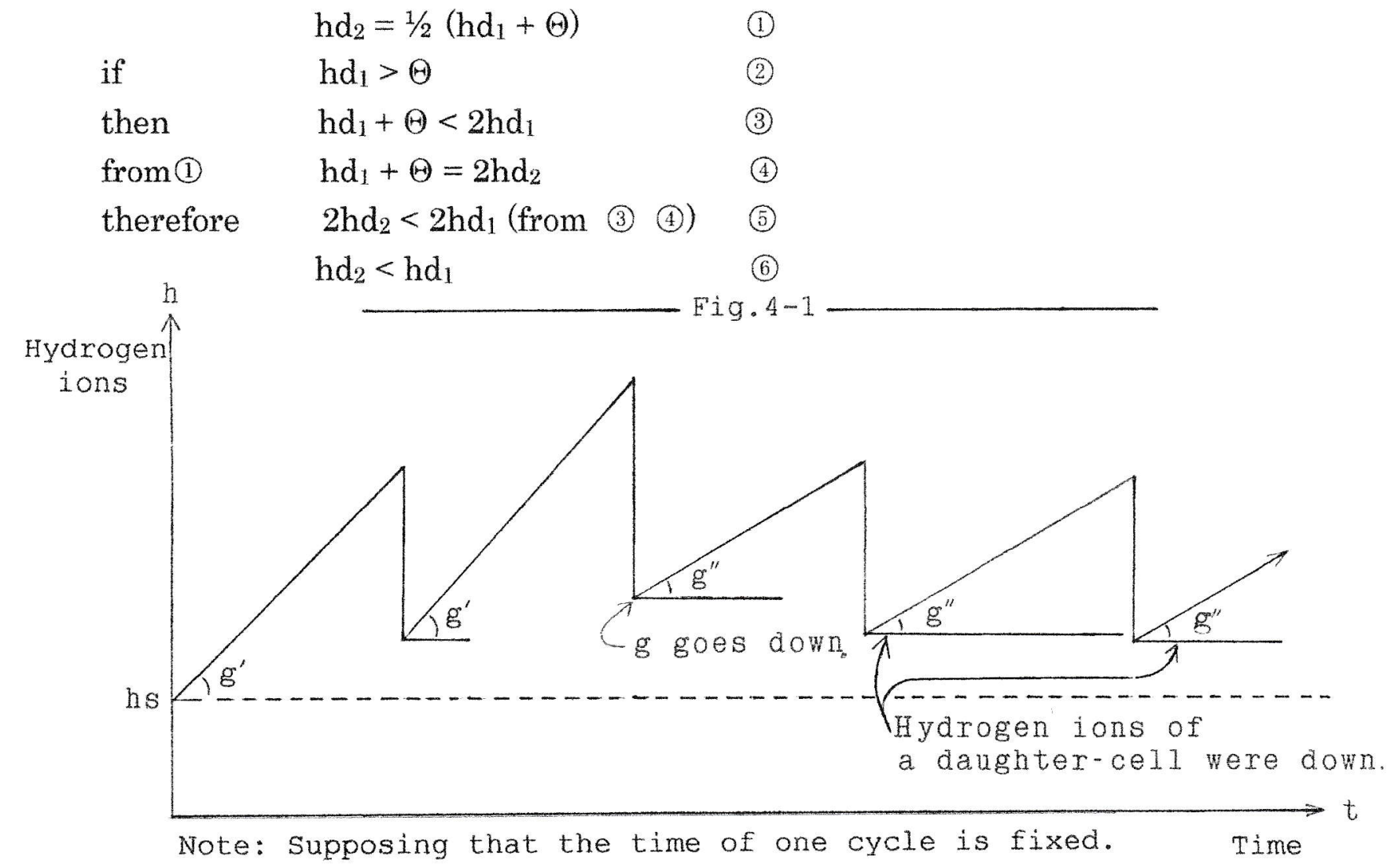


In the condition that hydrogen ions of a daughter-cell become less than hs ( $h$ s is the value of hydrogen ions to start the cell division), when $\mathrm{g}$ becomes less and less a necessary time to reach to hs becomes longer and longer. Therefore a rate of the cell division becomes slow. And provided $\mathrm{g}$ becomes zero, the cell division will stop.

This is represented graphically as the followings (Fig. 4-2).

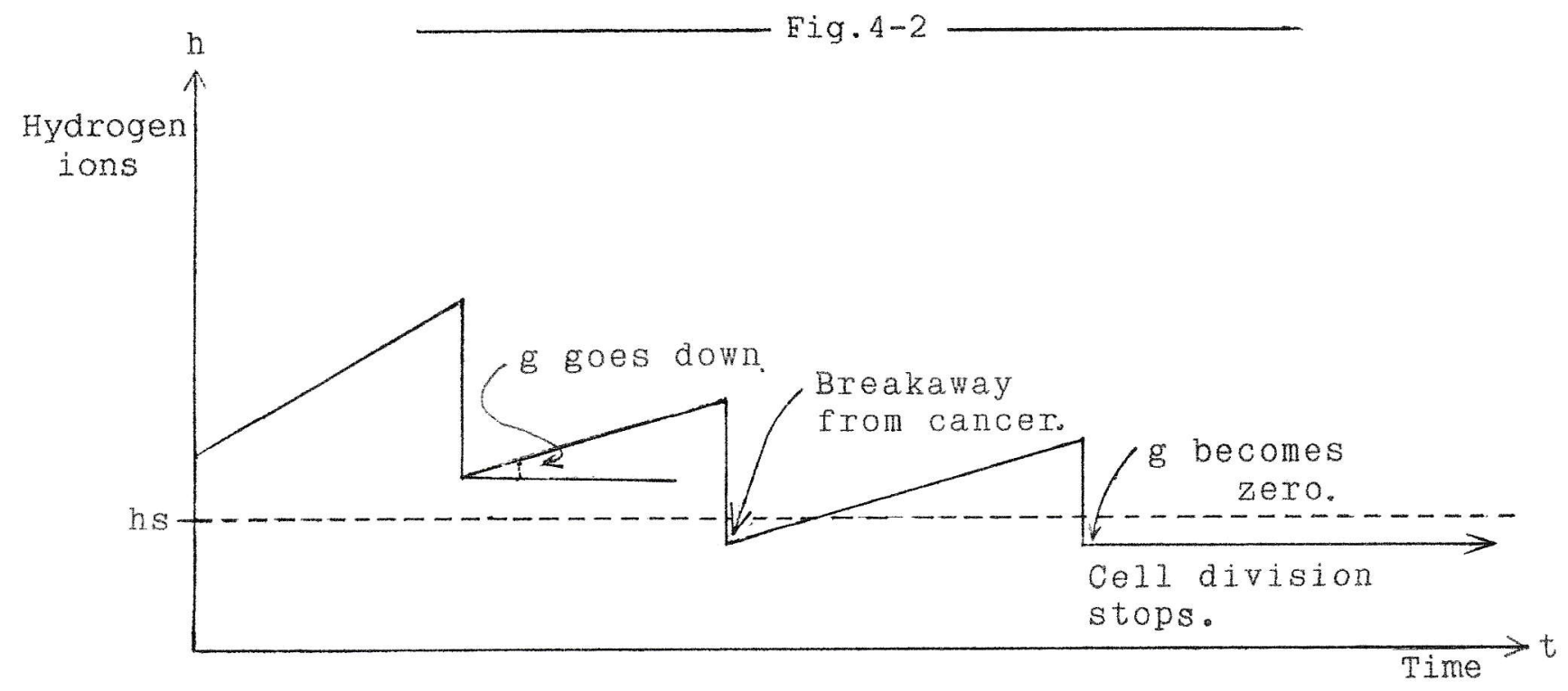

When the cell division becomes slower and stops, the fatal influence to a host will fade away. This is the cure of cancer.

2. The principle of a treatment for cancer is to supply oxygen to cancer cells and to remove hydrogen ions

Therefore a treatment for cancer is to reduce $\mathrm{g}$ ( $\mathrm{g}$ is the rate of generating hydrogen ions per a time). In a cell hydrogen ions are absorbed and removed by oxygen at the respiratory chain. Consequently one way to reduce $g$ is to supply oxygen as a hydrogen acceptor.

At the next sections I illustrate experimental ways with cultured cells to prove this hypothesis and some practical means of treatment for cancer of man.

\section{The experiments in cultured cells and the practical methods of medical treatment for cancer of human beings}

The following experiments and methods of medical treatment are presentations of fundamental principles, and are not results of actual experiments or treatments. Through the proceeding investigation, it can be thought that cancer cells will stop its multiplication and return to normal cells by the following methods. 
I hope that these presentations will proceed to a practical treatment for cancer of human beings through experiments in cultured cells, animal experiments and clinical demonstrations by biological and medical scientists who have a faculty of experiments and treatments.

(1)Supply oxygen to cultured cancer cells, and multiplication of cancer cells will stop

(1) Supply oxygen to cultured cancer cells, and cancer cells stop its multiplication and return to normal cells (Fig. 4-3)

This is the experiment in a laboratory dish to prove that supplying oxygen to cancer cells stops its multiplication and makes it return to normal cells.

In Fig. 4-3, cancer cells are cultured in a laboratory dish which is covered by a lid. And the lid has two tubes. One is for supplying oxygen, and the other is for exhausting used oxygen. The exhausting tube has a valve to regulate pressure within the laboratory dish. The temperature and the humidity within the laboratory dish is conserved same as a condition of an inside of the human body.

$100 \%$ of aerial oxygen is continued to supply to cancer cells within the laboratory dish through the supplying tube, and exhausted through the exhausting tube. And it is possible to apply pressure by regulating the pressure valve to increase the absorption of oxygen to cancer cells.

Fig.4-3

The experiment to confirm that supplying oxygen to cancer cells stops its multiplication and makes it return to normal cells

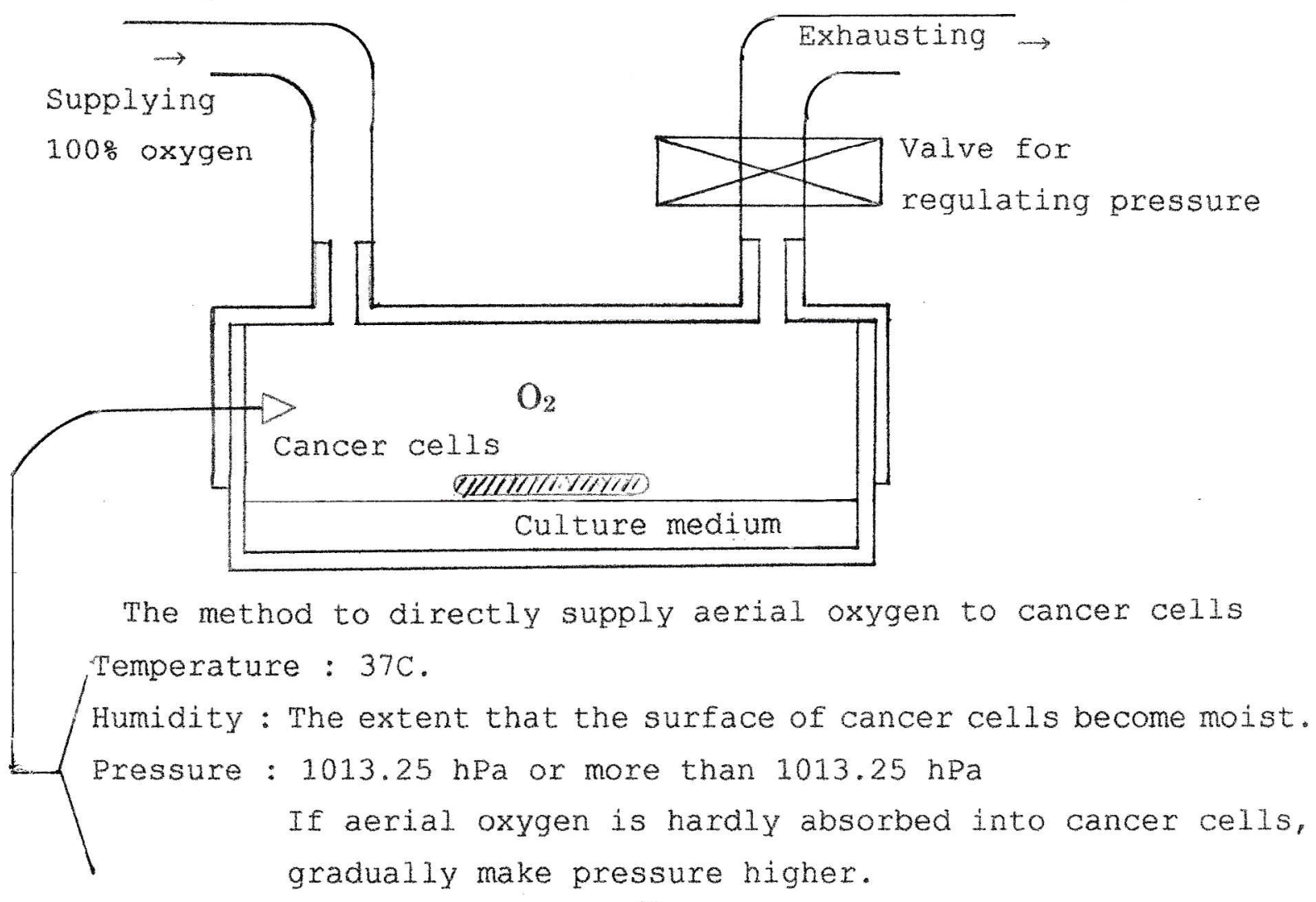


(2) Fill cancer cells of a laboratory dish with hemoglobin, and supply oxygen (Fig. 4-4)

To make cancer cells more easily to absorb oxygen, fill cancer cells with hemoglobin, and supply oxygen to a laboratory dish. In this arrangement oxygen is supplied certainly to cancer cells through hemoglobin.

Fig. 4-4

The experiment to confirm that supplying oxygen to cancer cells stops its multiplication and makes it return to normal cells (2)

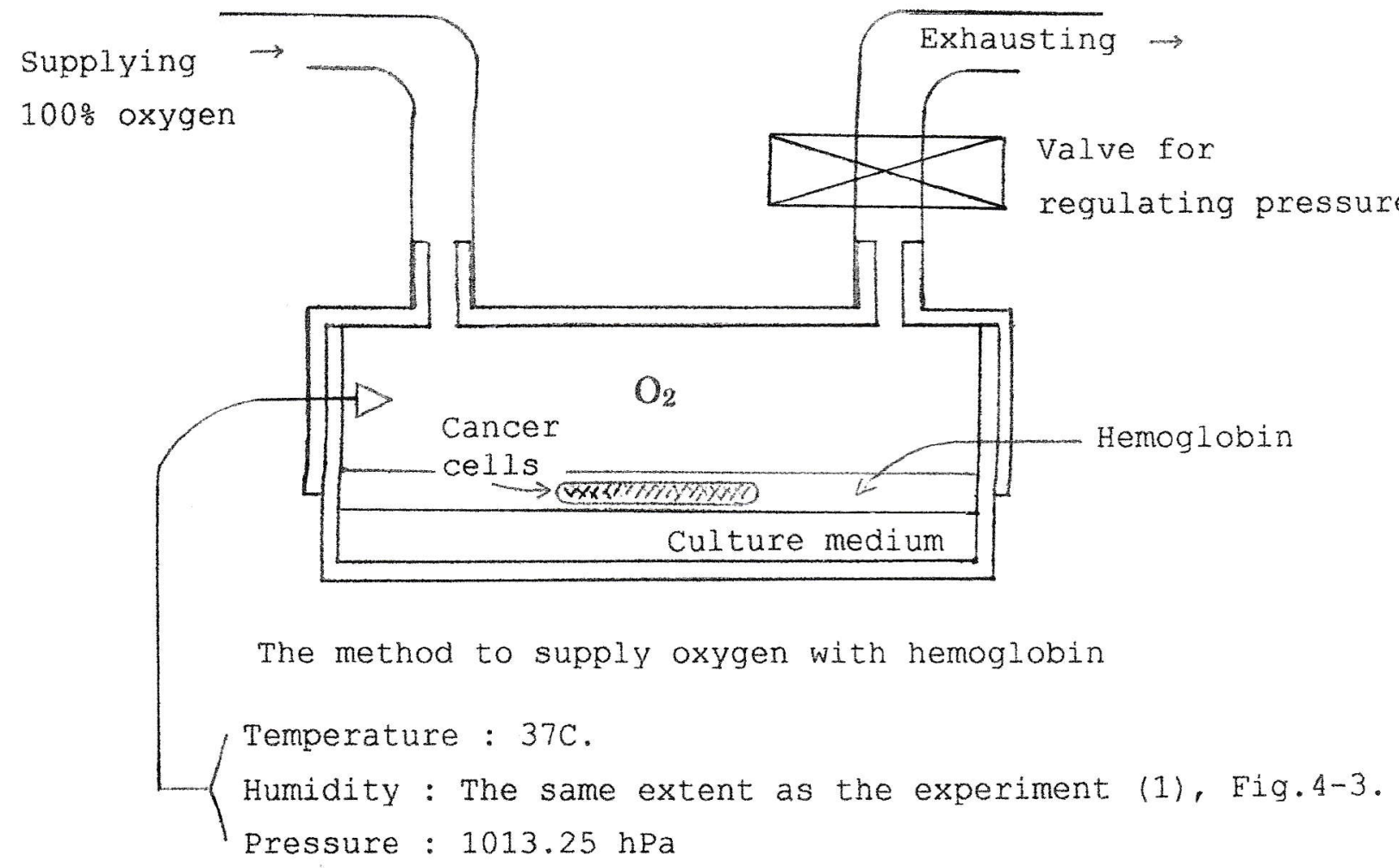

\section{(2)Methods of medical treatment for cancer of human beings}

(1) Breathe $100 \%$ oxygen and heighten density of oxygen in blood, promote the blood circulation and supply oxygen to cancer cells (Fig. 4.5)

First of all warm a body to promote blood circulation. And supply 100\% oxygen to the lungs. At the same time make a patient perform deep external respiration that a patient inhales to almost the maximum of the lung capacity and exhales to the minimum of the lungs. This method supplies much oxygen in high density to the whole body and ultimately to cancer cells by loading into blood. This method is available to all sorts of cancer because oxygen is supplied to the whole body. 
The treatment to supply oxygen by warming a body to promote blood circulation and inhaling 100 ox oxygen

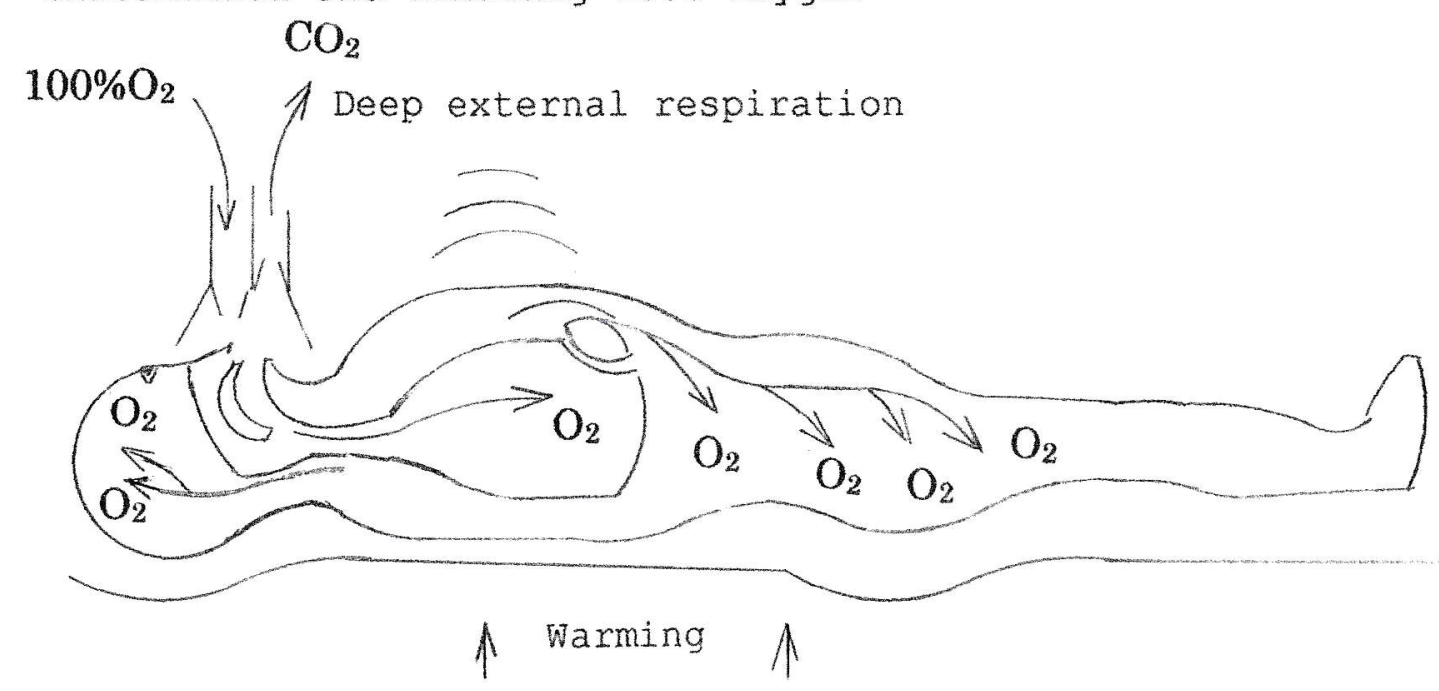

Promoting blood circulation by warming

Fig. 4-5

(2) Supply oxygen in high density with high pressure (Fig. 4-6)

A patient enters into the capsule that has two tubes for supplying oxygen and exhausting. The exhausting tube has a valve to regulate pressure of the capsule. Heighten the density of oxygen and the pressure in the capsule. Thus this method makes a degree of permeation into a body higher and supplies oxygen efficiently to cancer cells. And this method supplies oxygen to a whole of body, therefore it is available for any sort of cancer.

Making permeation of oxygen from the lungs to blood higher by heightening the pressure and the density of oxygen

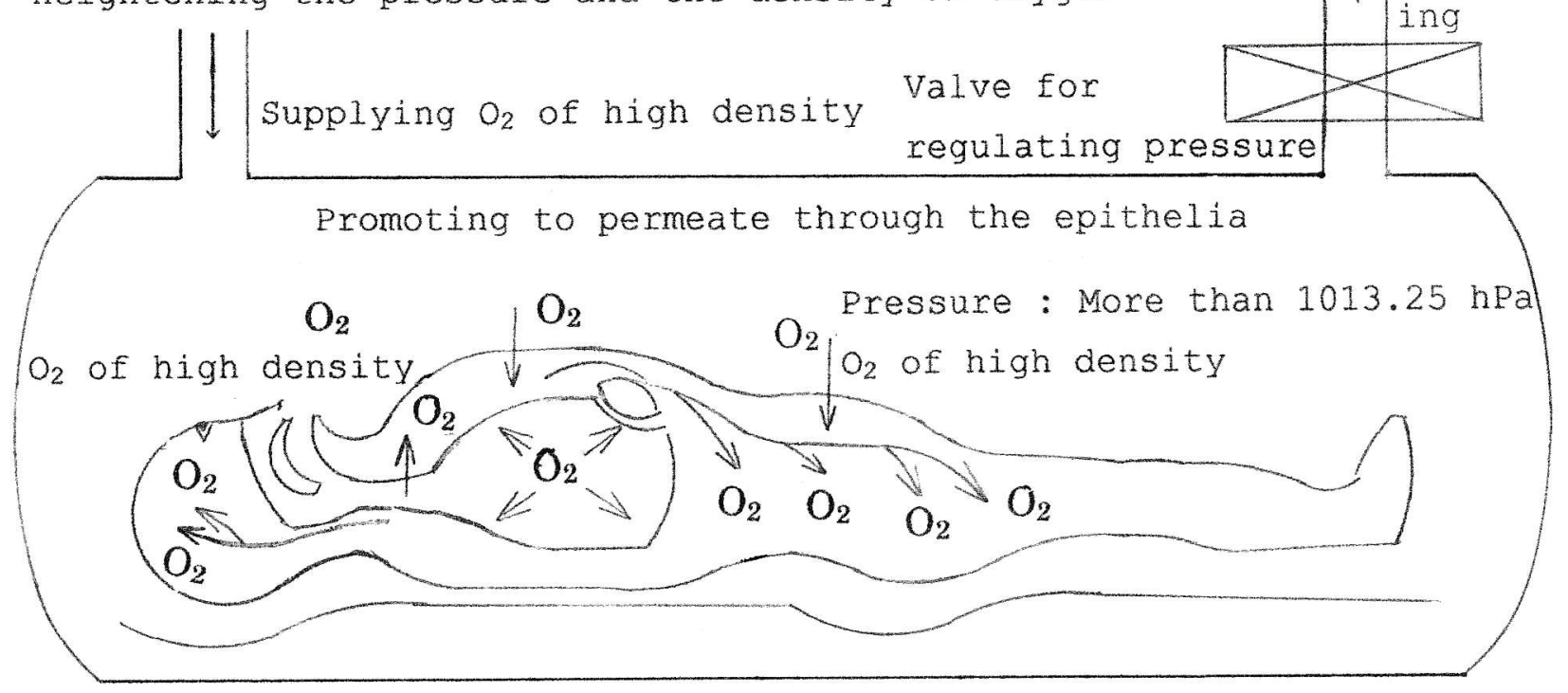

The treatment to supply oxygen under high density and high pressure Eig. 4-6 
(3) Supply oxygen to myeloid blood and cure myeloid leukemia (Fig.4-7)

This method is that, at first draw myeloid blood out of the bone marrow of a patient and blow oxygen into myeloid blood. And return it to the bone marrow. By repeating this operation, fill myeloid blood up with oxygen. And the multiplication of leukocyte will stop. It is the cure of myeloid leukemia.

The method to treat myeloid leukemia by supplying oxygen to myeloid blood

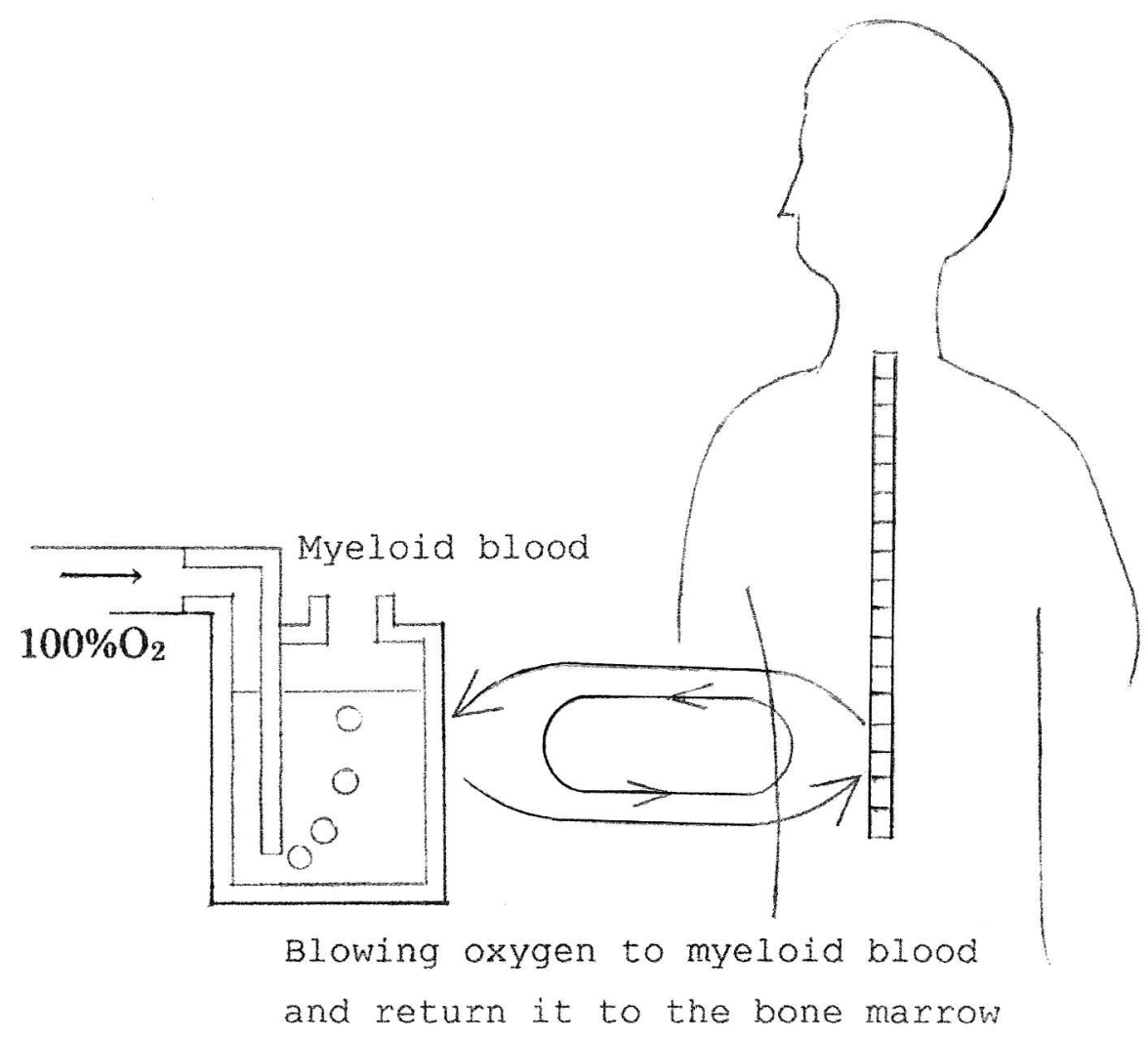

Fig. 4-7

\section{(4) Supply oxygen to digestive organs with catheters (Fig.4-8)}

Insert a catheter from the mouth into the stomach and supply oxygen to cancer cells of digestive organs such as the esophagus, the stomach, the duodenum and the pancreas.

Insert a catheter from the anus into the large intestine and supply oxygen directly to cancer cells of the large intestine.

This supply of oxygen to the digestive system can be expected to supply oxygen to the whole body through the epithelia of the digestive organ. 


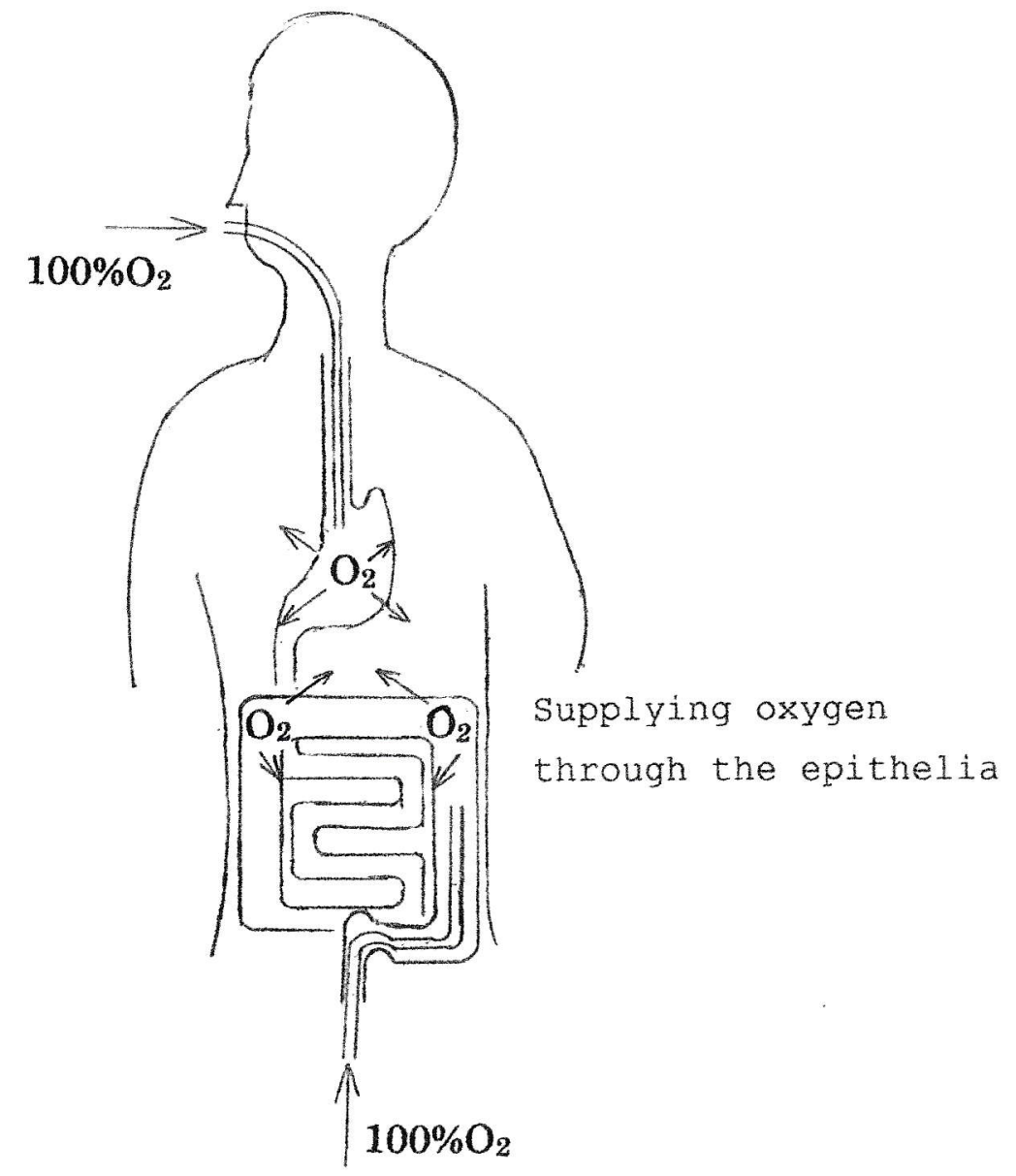

(5) Supply super-bubble water that contains super-minute oxygen through digestive organs (Fig.4-9)

This method is to drink super-bubble water that contains an enormous quantity of super-minute oxygen. This method is to supply oxygen to the whole body and ultimately to cancer cells through digestive organs. It is available to any sort of cancer because it supplies oxygen to the whole body. The investigation about the method to supply super-bubble water is proceeding, and is confirming to efficacy to cure for cancer. (Refer to references at the end of this treatise.) 
The method to supply oxygen by super-bubble water through digestive organs

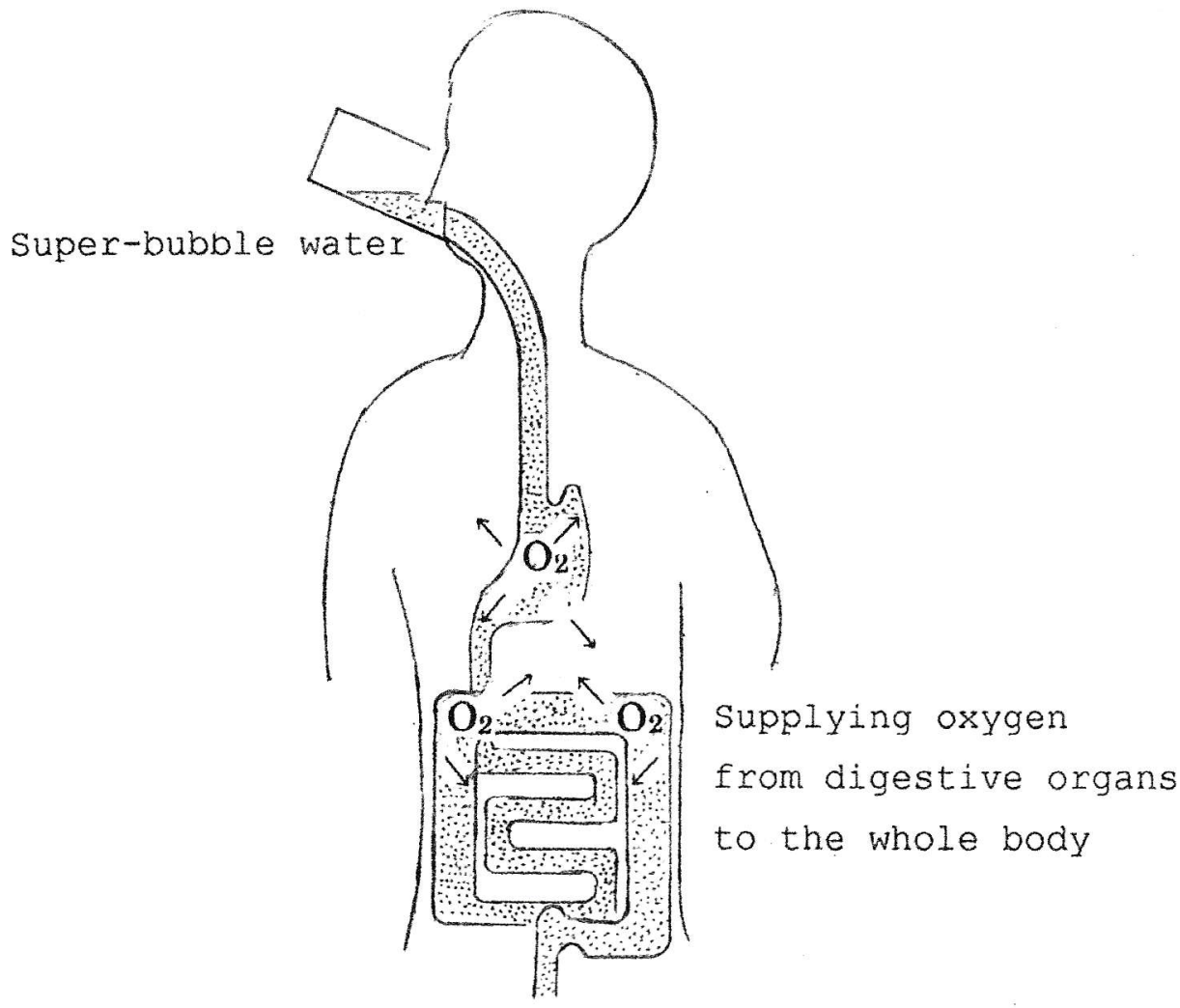

Fig. 4-9

(6) Change a hydrogen ion into a hydrogen molecule by offering an electron to a hydrogen ion for a treatment for lung cancer

DNA is divided by a hydrogen ion. Therefore if a hydrogen ion changes into a hydrogen molecule, it does not become a trigger of cell division. So by offering negative charge to the whole body or a part of cancer, hydrogen ions change to hydrogen molecules and become electrically neutral. And the rate of cell division of cancer will become down or cell division itself will stop.

In this method hydrogen molecules may emerge as gas. Therefore it is necessary to eliminate aerial hydrogen out of a body. Lung can exhaust aerial hydrogen. Therefore this method may be possible to apply to a treatment for lung cancer.

\section{REFERENCES}

To explain "supply oxygen and cancer cure", I have published treatises on my own account two times in 1981 and in 1986 as follows. This is the third treatise.

@ Nobuo Tomizawa An inquiry on the cause and treatment of cancer 
(Japanese version) 1981

@ Nobuo Tomizawa An approach to the Dynamic Mechanism for Carcinogenesis and Treatment of Cancer based on Theoretical Biology 1986

Concerning chapter 1 , section 3 , the experiment injecting liquid of concentrated grape sugar into a muscle

1. Kazuo Nakahara, Cancer, Iwanami-shoten, 88-89, 1976

Concerning chapter 1 section 4, generating hydrogen ions by irradiating radiation to the cell

2. Souhei Kondoh, Why is a human being weak to radiation? Japanese version, Kodansha, 87-93, 1986

Concerning chapter 1

3. J. D. Watson Molecular Biology of the Gene, $3^{\text {rd }}$ edition Japanese Version, Tokyo-kagakudojin 29-63, 1984

4. Shigeki Okayama, Yoshio Takahashi, Kunimitsu Wakamatsu, Osamu Koizumi, Life and Energy, Japanese version, Kyoritsu-shuppan, 12-108, 1981

Concerning chapter 2

5. James D. Watson Molecular Biology of the Gene, $3^{\text {rd }}$ edition, Japanese Version, Kagakudojin, second volume, 29-63, 91-121, 225-280, 283-317, $321-343,1984$

6. James D. Watson Molecular Biology of the Gene, $7^{\text {th }}$ edition, Japanese version, Tokyo Denki University, 257-311, 2017

7. Takaaki Tamura, Masami Muramatsu Fundamental Molecular Biology, $3^{\text {rd }}$ edition, Japanese version, Tokyo-Kagaku-Dojin 107-119, 2013

8. Dabid Sadava, H. Craig Heller, Gordon H. Orians, William K. Purves, and David M. Hillis. LIFE $8^{\text {th }}$ edition, chapter 2, 3 and 4 . Japanese version, the second volume, Kodansha, 153-215, 2010

\section{Concerning chapter 3}

9. Yasuo Hotta: Structure and Function of the cell II, Japanese version Iwanami-shoten, 171-216, 1978

10. Akira Makita: Structure and Function of the cell II, Japanese version Iwanami-shoten, 217-266, 1978

Concerning chapter 4, section 3, (2), (5), Supply super-bubble water that contains super-minute oxygen through the digestive organ

11. Masaki Iijima, Navchaa Gonbodorj, Yoshiaki Tachibana, Takehiko 
11. Masaki Iijima, Navchaa Gonbodorj, Yoshiaki Tachibana, Takehiko Yokobori, Kyoko Honma, Takashi Nakano, Takayuki Asao, Ryusuke Kuwahara, Kazuhiro Aoyama, Hidehiro Yasuda, Matthew Kelly, Hiroyuki Kuwano and Dai Yamanouchi, Development of single nanometer-sized ultrafine oxygen bubbles to overcome the hypoxia-induced resistance to radiation therapy via the suppression of hypoxia-inducible factor" $1 \alpha, 2017$ 